OPEN ACCESS

Edited by:

Chang Liu,

University of Hohenheim, Germany

Reviewed by:

Raphael Mercier,

Max Planck Institute for Plant

Breeding Research, Germany

Stefan Heckmann,

Leibniz Institute of Plant Genetics and

Crop Plant Research (IPK), Germany

*Correspondence:

Christophe Lambing

cal66@cam.ac.uk

Specialty section:

This article was submitted to

Plant Cell Biology,

a section of the journal

Frontiers in Plant Science

Received: 12 May 2021

Accepted: 17 June 2021

Published: 19 July 2021

Citation:

Kuo $P$, Da Ines $O$ and

Lambing C (2021) Rewiring Meiosis

for Crop Improvement.

Front. Plant Sci. 12:708948.

doi: $10.3389 /$ fpls.2021.708948

\section{Rewiring Meiosis for Crop Improvement}

\author{
Pallas Kuo', Olivier Da Ines ${ }^{2}$ and Christophe Lambing ${ }^{1 *}$ \\ 'Department of Plant Sciences, University of Cambridge, Cambridge, United Kingdom, ${ }^{2}$ Institut Génétique Reproduction et \\ Développement (iGReD), Université Clermont Auvergne, UMR 6293 CNRS, U1103 INSERM, Clermont-Ferrand, France
}

Meiosis is a specialized cell division that contributes to halve the genome content and reshuffle allelic combinations between generations in sexually reproducing eukaryotes. During meiosis, a large number of programmed DNA double-strand breaks (DSBs) are formed throughout the genome. Repair of meiotic DSBs facilitates the pairing of homologs and forms crossovers which are the reciprocal exchange of genetic information between chromosomes. Meiotic recombination also influences centromere organization and is essential for proper chromosome segregation. Accordingly, meiotic recombination drives genome evolution and is a powerful tool for breeders to create new varieties important to food security. Modifying meiotic recombination has the potential to accelerate plant breeding but it can also have detrimental effects on plant performance by breaking beneficial genetic linkages. Therefore, it is essential to gain a better understanding of these processes in order to develop novel strategies to facilitate plant breeding. Recent progress in targeted recombination technologies, chromosome engineering, and an increasing knowledge in the control of meiotic chromosome segregation has significantly increased our ability to manipulate meiosis. In this review, we summarize the latest findings and technologies on meiosis in plants. We also highlight recent attempts and future directions to manipulate crossover events and control the meiotic division process in a breeding perspective.

Keywords: meiosis, meiotic recombination, centromere, telomere, plant, chromatin, epigenetic, ploidy

\section{CHROMATIN AND RECOMBINATION IN MEIOSIS}

\section{Meiotic Recombination}

Meiosis is a specialized cell division taking place in sexually reproducing organisms during which a cell undergoes two rounds of chromosome segregation to form four daughter cells of halved ploidy. Each daughter cell contains a set of chromosomes with varying genetic contents to the others due to genetic exchanges and random assortment of homologous chromosomes and sister chromatids. The first meiotic segregation faces a unique situation whereby chromosomes undergo recombination events leading to reciprocal exchanges between homologs, also called crossovers (COs; Mercier et al., 2015). COs are important to create novel genetic diversity, and this natural process is utilized during breeding strategies to break the linkage between genes, facilitating the removal of unfavorable genetic elements or improving the mapping of quantitative trait locus (Mercier et al., 2015). 
Meiotic recombination initiates with the formation of programmed DNA double-strand breaks (DSBs) induced by a topoisomerase-like complex related to the archaeal TopoVI DNA topoisomerase (Topo VI). Topo VI is an heterotetrameric enzymatic complex comprising two $\mathrm{A}$ and two B subunits and catalyzing DNA strand breakages (Bergerat et al., 1997). In meiosis, SPO11 and MTOPVIB form a complex with topoisomerase-like activity to create a DSB onto which SPO11 remains covalently bound to the DSB end via a phosphotyrosyl bond (Robert et al., 2016; Vrielynck et al., 2016). SPO11 forms meiotic DSBs as a homodimer in animals and fungi, and as a SPO11-1/SPO11-2 heterodimer in plants (Mercier et al., 2015). Studies of SPO11 proteins between plant species reveal that the number of orthologs varies greatly (Sprink and Hartung, 2014; Da Ines et al., 2020). In Arabidopsis thaliana, three SPO11 paralogs are identified but only SPO11-1 and SPO11-2 are involved in meiotic DSB formation (Hartung et al., 2007). Rice has five SPO11 paralogs and only SPO11-1 and SPO11-2 have a confirmed role in meiosis while loss of spo11-4 has no meiotic defects (Yu et al., 2010; Fayos et al., 2020). The high number of SPO11 paralogs in plants makes genetic engineering to control meiotic recombination more challenging. However, SPO11 orthologs are sufficiently conserved between plant species as to complement each other's loss of function mutations. For instance, expression of bread wheat SPO11-2 restores fertility in Arabidopsis spo11-2 (Benyahya et al., 2020; Da Ines et al., 2020) while expression of bread wheat SPO111-5D restores fertility in both rice and Arabidopsis spo11-1 (Da Ines et al., 2020). Additional proteins are required for DSB formation and appear conserved between plants (Jing et al., 2019). For example, Arabidopsis PRD1 (De Muyt et al., 2007), PRD2 and PRD3 (De Muyt et al., 2009), and DFO (Zhang et al., 2012) are all essential for the formations of meiotic DSB. Similarly, rice prd1 (Shi et al., 2021), mtopVIb (Fu et al., 2016; Xue et al., 2016) and prd3/pair1 (Nonomura et al., 2004), and maize mtopVIb (Jing et al., 2020) are defective in DSB formation.

Cytological studies using DNA damage markers, such as $\gamma-\mathrm{H} 2 \mathrm{AX}$ and RAD51, revealed the formation of a large number of DSBs in early meiosis. It is estimated that between 150 and 200 meiotic DSBs are formed in Arabidopsis and between $\sim 200$ and 2,000 in crops with larger genome (Ferdous et al., 2012; Higgins et al., 2012; Sidhu et al., 2015; Gardiner et al., 2019; Benyahya et al., 2020). DSBs are formed on the chromatin which is organized in arrays of loops anchored to a proteinaceous linear structure called the chromosome axis (Zickler and Kleckner, 1999; Kleckner, 2006). In plants, components of the chromosome axis include meiotic cohesin REC8 (Chelysheva et al., 2005; Golubovskaya et al., 2006), HORMA-domaincontaining proteins ASY1/PAIR2 (Armstrong et al., 2002; Nonomura et al., 2006), and coiled-coil proteins ASY3/PAIR3/ DSY2 (Wang et al., 2011; Ferdous et al., 2012; Lee et al., 2015) and ASY4 (Chambon et al., 2018; Osman et al., 2018). The axis proteins ASY3/DSY2/Red1 are essential for DSB formation (Panizza et al., 2011; Ferdous et al., 2012; Lee et al., 2015), and chromosome axis length covaries with the number of DSB markers on a per-nucleus basis in Arabidopsis and budding yeast, highlighting the important regulatory functions of the axis on recombination initiation (Wang et al., 2019b; Lambing et al., 2020b).

Following DSB formation, DSB ends are resected by the MRN/COM1 complex to form 3' overhang single-stranded DNA (ssDNA) onto which RPA, RAD51, and DMC1 are recruited to form nucleoprotein filaments (Mercier et al., 2015). Multiple strand invasions of the chromosome filaments favor homologous chromosome alignment and are critical for chromosome pairing in most species (Cloud et al., 2012; Hong et al., 2013). Successful pairing leads to installation of a tripartite structure called the synaptonemal complex (SC) which consists of a transverse filament formed with ZYP1 and connecting the two homologous axes (Mercier et al., 2015). The SC initiates at recombination sites (Zhang et al., 2014a; Lambing et al., 2015), and several lines of evidence suggest that SC components regulate $\mathrm{CO}$ formation (Higgins et al., 2005; Barakate et al., 2014; Chen et al., 2015; Voelkel-Meiman et al., 2015; Capilla-Perez et al., 2021; France et al., 2021). Meiotic DSB repair results in a CO or a non-CO, with a possibility of gene conversion in either case (Berchowitz and Copenhaver, 2010). Gene conversions are short unidirectional exchanges (few hundreds base pairs) of genetic information between chromosomes. Gene conversion events are rare, and the control over gene conversion is not well understood. The frequency of gene conversion per meiosis on a given locus is estimated between $\sim 10^{-4}$ and $10^{-6}$ (Sun et al., 2012; Drouaud et al., 2013; Wijnker et al., 2013). Gene conversion frequency is associated with $\mathrm{MSH} 4$, a protein required for CO formation (Drouaud et al., 2013), and can be detected on the heterochromatin regions where COs are repressed (Shi et al., 2010).

How a DSB's fate is determined is still not fully understood, but it is thought that pro- and anti-CO pathways influence the repair outcome at DSB sites (Mercier et al., 2015). For example, a set of proteins collectively named "ZMM" (SHOC1, PTD, HEI10, ZIP4, MER3, MSH4, and MSH5 in Arabidopsis) stabilizes inter-homolog joint molecules and promotes CO formation (Mercier et al., 2015). In contrast, anti-CO proteins, such as FANCM, BLM/RECQ4, TOP3 $\alpha$, FIGL1, disengage joint molecules via helicase or topoisomerase activities, and repress CO formation (Crismani et al., 2012; Mercier et al., 2015; Seguela-Arnaud et al., 2015). During meiotic DSB repair, the ssDNA ends elongate via DNA synthesis using the homologous chromosome as a template. If heterozygosity is shared between the homologous template and the ssDNA end, disengagement of this ssDNA and repair by an anti-CO pathway could lead to a non-CO associated with a gene conversion (Berchowitz and Copenhaver, 2010). Recent studies in budding yeast indicate that complex partner switches may be common during meiosis, creating chromatids with mosaic allelic patterns (Mcmahill et al., 2007; Marsolier-Kergoat et al., 2018).

Each bivalent chromosome must form at least one $\mathrm{CO}$, termed an obligate $\mathrm{CO}$, to form the physical link between chromosomes which is essential to ensure proper chromosome segregation in meiosis. In most species, CO formation is limited to 1-3 per chromosome pair (Jones and Franklin, 2006; Mercier et al., 2015). Several factors have been reported to contribute 
to these phenomena: $\mathrm{CO}$ homeostasis (Henderson and Keeney, 2004), CO interference (Kleckner et al., 2004), limited amount of pro-CO factors (Ziolkowski et al., 2017), and the presence of anti-CO factors (Crismani et al., 2012; Girard et al., 2015; Seguela-Arnaud et al., 2015). CO homeostasis is a phenomenon buffering changes in DSB number for the maintenance of total COs. In this context, an elevation or a decrease in DSBs does not impact $\mathrm{CO}$ number. While CO homeostasis is observed in budding yeast (Martini et al., 2006), it may be different in plants (Sidhu et al., 2015; Xue et al., 2018). In contrast, CO interference is a phenomenon resulting in the non-random distribution of COs whereby the formation of one $\mathrm{CO}$ inhibits the formation of additional COs in adjacent regions, thus preventing clustering of COs (Wang et al., 2015). Although factors involved in this phenomenon are unclear, it has been suggested that a combination of physical stresses generated from the expansion and contraction of chromatin compressing the chromosome axis during prophase I, combined with the diffusion of proteins along the axis, contribute to the establishment of an interfering signal (Wang et al., 2015; Zhang et al., 2018). In accordance with this model, components of the chromosome axis have been implicated in $\mathrm{CO}$ interference in budding yeast (Zhang et al., 2014b), Caenorhabditis elegans (Libuda et al., 2013; Zhang et al., 2018), and Arabidopsis (Lambing et al., 2020a; Capilla-Perez et al., 2021; France et al., 2021). However, the chromosome axis in itself may not be sufficient to impose $\mathrm{CO}$ interference since axis is formed in asy 1 and zyp 1 mutant lines in which interference is lost (Lambing et al., 2020a; Capilla-Perez et al., 2021; France et al., 2021).

\section{Chromatin and DSB Hotspots}

DSBs are not randomly formed on the genome. Instead, they are enriched in nucleosome-depleted regions (Pan et al., 2011; Lam and Keeney, 2015; Choi et al., 2018). It appears that regions with high nucleosome occupancy prevent SPO11 accessibility and thus restrict DSB formation. DSB formation also takes place in the context of chromatin loops anchored to a chromosome axis. Counterintuitively, certain components of the DSB machinery are found associated with the chromosome axis while DSBs are located in the chromatin loops, away from the axial sites in budding yeast (Panizza et al., 2011; Stanzione et al., 2016). To reconcile the two observations, it was proposed that chromatin loops are tethered to the axis prior to DSB formation. In support of this model, Spp1, a PHD finger-domain protein, was found to interact with H3K4me3 modifications located on the chromatin loop, and with Mer2 protein, a component of the DSB machinery located on the axis in budding yeast (Acquaviva et al., 2013; Sommermeyer et al., 2013). This observation indicates a complex interaction between chromatin loop organization, epigenetics marks, and recombination. Interestingly, DSB hotspots are enriched at the $5^{\prime}$ end of genes, and axis components are enriched at the $3^{\prime}$ end of genes and are influenced by transcriptional activity in budding yeast (Pan et al., 2011; Lam and Keeney, 2015; Medhi et al., 2016). Arabidopsis DSB maps show enrichment of DSBs at the $5^{\prime}$ and $3^{\prime}$ end of genes, in regions of low nucleosome occupancy and with markers of open chromatin (e.g., H3K4me3).
DSBs are correspondingly depleted in heterochromatic regions that are enriched in transposons, GC content, and DNA methylation (Choi et al., 2018). Consistent with budding yeast, ChIP-seq of Arabidopsis axis protein revealed that REC8 and DSBs occupy distinct sites. REC8 also shows a preferential polarization toward the end of genes that is influenced by transcriptional activity (Lambing et al., 2020b). Comparing genome-wide Arabidopsis axis and DSB profiles revealed no correlation between the enrichment of SPO11-1-oligos and REC8 or ASY1 over genes, indicating that although the chromosome axis is important for DSB formation, the amount of axis protein does not specify the frequency of DSBs locally (Lambing et al., 2020a,b). Additional factors likely influence the local frequency of DSB formation.

\section{Influence of Heterochromatin and Centromeres on Meiosis}

Although COs are suppressed over the heterochromatin, a substantial number of DSBs has been detected over the pericentromeric heterochromatic regions, including at transposons, in Arabidopsis (Choi et al., 2018; Underwood et al., 2018) and maize (He et al., 2017). The maize genome is $\sim 85 \%$ transposons, and comparative analysis shows that DSBs are distributed along the entire chromosomes without specific polarization, while COs are skewed toward the end of the chromosomes (He et al., 2017). Few COs were reported in the heterochromatic knob regions in maize but at much lower frequency than its DSB frequency (Stack et al., 2017). Thus, an interesting possibility is that recombination may not be fully suppressed on the heterochromatin and centromeres but rather channeled to favor non-CO outcomes, such as inter-sister repair. Indeed, gene conversions were detected in maize centromeric regions (Shi et al., 2010).

$\mathrm{CO}$ suppression over the centromeric heterochromatin is widely conserved (Ellermeier et al., 2010; Li et al., 2015; Phillips et al., 2015). The molecular mechanisms allowing this suppression are not clear, but appear instrumental since centromeric COs have been associated with increased rates of mis-segregation and aneuploidy in multiple species (Fernandes et al., 2019). On the other hand, understanding suppression of $\mathrm{CO}$ at or close to the centromeres is of particular importance for breeding, given that lack of meiotic $\mathrm{CO}$ in pericentromeric regions is a major bottleneck in varietal development of crop plants.

Centromeres are the sites of kinetochore assembly which enable microtubule fiber attachment and thus faithful segregation of chromosomes during mitotic and meiotic division. The structure and organization of the centromeres vary considerably between species with centromeres occupying a short sequence, a region or even the entire chromosome (Steiner and Henikoff, 2015; Talbert and Henikoff, 2020). Point centromeres are typical in budding yeast (Prosee et al., 2020) while C. elegans and some plants display holocentric chromosomes where the whole chromosome acts as a centromere (Melters et al., 2012). Holocentric chromosomes impose a specific problem to meiosis and how meiosis is remodeled in holocentric plants is being 
extensively investigated (Marques and Pedrosa-Harand, 2016). Most plants and mammals, however, exhibit regional centromeres. In plants, regional centromeres are largely composed of centromeric satellite repeats and centromeric retrotransposon arrays that can be several megabases long (Lamb et al., 2007; Ma et al., 2007; Fernandes et al., 2019). Yet, a centromere is generally not defined by a specific DNA sequence but rather by the presence of the specific histone $\mathrm{H} 3$ variant $\mathrm{CenH} 3$ (mammalian CENP-A), which acts as a particular epigenetic mark that establishes functional centromeres. CenH3 is present at all functional centromeres independently of their DNA sequence, and this epigenetic specification of centromere identity is broadly conserved in eukaryotes (Steiner and Henikoff, 2015; Fernandes et al., 2019; Talbert and Henikoff, 2020).

How centromeres function during meiosis in plants is still poorly understood but a number of studies have described the essential role of early centromere associations in homologous chromosome recognition, pairing, and subsequent synapsis during meiosis (reviewed in Da Ines and White, 2015; Sepsi and Schwarzacher, 2020). Remarkably, early centromere associations seem not directly mediated by DSB formation and recombination but rather by local chromatin homology, although stabilization of centromere pairing appears to be partially dependent on recombination initiation (Da Ines et al., 2012; Da Ines and White, 2015; Sepsi and Schwarzacher, 2020). Centromere association requires active centromeres and the presence of functional CENH3 variants (Zhang et al., 2013). Thus, despite high-DNA sequence homology, initial centromere interactions are driven by specific chromatin structure and centromeric proteins. In particular, early centromere associations are strongly dependent on the REC8 cohesin enrichment as well as DNA repeats organization at centromeres. In wheat, recent work has revealed that centromere satellite organization has diverged in the different wheat sub-genomes and these rearrangements of CENH3 nucleosomes likely influence centromere interaction and further homologous chromosome pairing (Su et al., 2019).

It is possible that early centromere association may impede access of the recombination machinery and thereby may play a key role in suppressing $\mathrm{CO}$ at centromeres. This is supported by the recent demonstration that REC8 enrichment is strongly correlated with suppression of meiotic DSBs and crossovers in Arabidopsis (Lambing et al., 2020b). Given that REC8 cohesin protein is highly enriched at centromeric sites from early meiosis I up to meiosis II and that centromere coupling and pairing also require the presence of REC8 (Cai et al., 2003; Zhang et al., 2013), it is conceivable that early centromere associations are intricately linked to suppression of recombination at centromeres.

\section{ENGINEERING MEIOTIC RECOMBINATION}

\section{Increasing Meiotic Recombination Genome Wide}

In most plants, only few COs are formed on each chromosome per meiosis and this phenomenon limits the potential to create novel genetic diversity (Mercier et al., 2015). This is caused in part by a limited amount of pro-CO factors, the repressive activity of anti-CO factors and the action of $\mathrm{CO}$ interference. The majority of COs is formed by the ZMM pathway. Among actors of this pathway, the E3 ligase HEI10 is dosage-dependent for recombination, with an increase in HEI10 expression being sufficient to increase the total genetic map length by 2 -fold in hybrid Arabidopsis, but with limited effect on the $\mathrm{CO}$ rate over the heterochromatic regions (Ziolkowski et al., 2017). Overexpression of HEI10 in Arabidopsis is also found to decrease $\mathrm{CO}$ interference although it is unclear how HEI10 impacts this process (Serra et al., 2018). The regulation of HEI10 dosage is a promising avenue to increase CO number in crops by stabilizing the recombination events maturing into class I COs and reducing the strength of $\mathrm{CO}$ interference. Recent studies identified protein phosphatase X1 and ZYP1/ ZEP1 as additional factors limiting class I CO formation suggesting that other strategies may be possible to increase class I CO rate (Wang et al., 2010, 2015; Capilla-Perez et al., 2021; France et al., 2021; Nageswaran et al., 2021).

Several anti-CO factors affecting class II COs have been identified with non-functional redundancy (Mercier et al., 2015; Wang and Copenhaver, 2018). For instance, mutations in fancm helicase and recq4 helicase or recq4 and figl1/flip AAA-ATPase complex cause a 10 -fold elevation in the $\mathrm{CO}$ rate across several genetic intervals in inbred Arabidopsis (Fernandes et al., 2018). This strategy was successfully transferred into crops with recq4 mutant showing a significant increase in crossover frequency in rice, tomato, and pea (Mieulet et al., 2018; De Maagd et al., 2020). Surprisingly, the extra COs formed in anti-class II CO mutants are present in regions with low degree of polymorphism (Fernandes et al., 2018; Blackwell et al., 2020). In particular, fancm recombination phenotype seems to be sensitive to the hybrid context as it can be detected in brassica, pea, and rice but not in Arabidopsis, tomato and wheat hybrid lines. It was postulated that a high degree of polymorphism in the hybrid lines could interfere with fancm-dependent CO formation (Blary et al., 2018; Mieulet et al., 2018; De Maagd et al., 2020; Raz et al., 2020).

The effect of combining HEI10 over-expressor with the repression of recq4 was tested, and the study showed a cumulative effect on CO frequency in hybrid Arabidopsis transgenic lines. However, heterochromatin recombination was not substantially increased in these lines and this strategy may have a more limited effect on crop genomes with large heterochromatin composition (Serra et al., 2018).

\section{Modulation of the Recombination Landscape}

Meiotic recombination is not uniformly distributed along plant genomes which restricts the potential for crop improvement during breeding. In maize and barley, about $20 \%$ of all genes are located in heterochromatin, where recombination cold spot regions reside (Taagen et al., 2020), and a remodeling of the recombination landscape toward these regions could facilitate the introduction of genetic diversity. A striking negative correlation exists between $\mathrm{CO}$ rate, transposon content, and DNA methylation in plants (Lambing et al., 2017). In non-CG DNA methylation and H3K9me2 Arabidopsis mutant lines, 
the recombination landscape is altered with increased COs in centromere-proximal regions. Although DSBs are also increased, a significant deficit in DSB yield remains visible on the heterochromatin in $\mathrm{H} 3 \mathrm{~K} 9 \mathrm{me} 2$-deficient mutant line, and this may be an important limiting factor for CO formation in Arabidopsis heterochromatin (Underwood et al., 2018). A direct translation of these findings to economically important crops is challenging. Epigenetic mutants in plants with larger genomes show alterations in vegetative development and fertility defects (Li et al., 2014; Tan et al., 2016; Corem et al., 2018). Alternative strategies could overcome these limitations. For example, transient silencing of epigenetic genes in reproductive tissues using virus-induced gene silencing (VIGS) could have an effect on the recombination landscape while preserving plant development.

Meiotic-specific factors closely associated with recombination molecules are likely more promising targets for the control of CO landscape. For example, components of the chromosome axis are involved in the decision between inter-sister and inter-homolog recombination and Arabidopsis ASY1 and ASY3 promote CO formation (Lambing et al., 2020a). Arabidopsis ASY1 ChIP sequencing revealed that ASY1 is enriched over the centromere-proximal regions, and a gradual reduction of ASY1 is associated with a remodeling of the COs from the centromere-proximal to the distal regions (Lambing et al., 2020a). It is speculated that the distal regions are crossover prone regions due to the early homologous pairing of the telomeres while the proximal regions are crossover prone due to the enrichment of ASY1 (Armstrong et al., 2001; Lambing et al., 2020a; Figure 1C).

The CO landscape in cereals is distinct from Arabidopsis and COs are exclusively formed in distal ends of the chromosomes (Figure 1; Phillips et al., 2015; Osman et al., 2021). Moreover, the spatio-temporal formation of the chromosome axis which is observed from immunostaining of ASY1, the deposition of ZYP1 which marks synapsis between homologous chromosomes, and the formation of DSBs differ significantly between cereals and Arabidopsis (Figures 1A,C). For example, axis, synapsis, and DSB formation are initiated on the distal regions before being detected on the interstitial and centromere-proximal regions in barley and wheat (Higgins et al., 2012; Lambing et al., 2017; Desjardins et al., 2020; Osman et al., 2021). In contrast, no polarization of axis formation or DSB formation is detected in Arabidopsis (Lambing et al., 2017; Figure 1A). It is conceivable that COs are exclusively distal in cereals because the distal regions experience first the formation of DSBs and the pro-CO activity of ASY1 (Figures 1B,C). In this context, it is important to remodel ASY1 ons the chromosomes to achieve a remodeling of the CO landscape in cereals. Indeed, this can be achieved by increasing the temperature in barley (Higgins et al., 2012). The change of temperature reduces the polarization of axis formation, and ASY1 is detected more evenly on the chromosomes which is associated with an elevation of interstitial and centromereproximal chiasmata (Higgins et al., 2012). However, this strategy may not be applicable to every crops, as seen in the observation that wheat recombination is only slightly and locally altered at high temperature (Coulton et al., 2020).

\section{Targeted Recombination}

Targeting recombination is potentially a preferred strategy compared to a genome-wide change in $\mathrm{CO}$ frequency, because it allows precise positioning of recombination events on the genome. This could be achieved by targeting recombination proteins to a specific locus or to locally alter the epigenome. DSBs are generally enriched in promoters, introns, and terminators of genes (Choi et al., 2018) and are depleted in exonic regions that are enriched in nucleosome and axis REC8 cohesin (Figure 2B; Choi et al., 2018; Lambing et al., 2020b). Electron microscopy studies show that the chromosome axis forms an electron dense structure (Kleckner, 2006) and the compact structure of the axis could inherently prevent DSB formation even if SPO11 is targeted to this region. Therefore, a fine analysis of the chromatin landscape appears important for the design of targeted recombination to maximize the efficiency of DSB formation.

CO cold spots have generally low DSB frequency and are enriched in nucleosome density, DNA methylation, and epigenetic silencing marks (Yelina et al., 2015; Choi et al., 2018; Underwood et al., 2018). Loss of DNA methylation is associated with a gain of DSBs in Arabidopsis (Choi et al., 2018; Underwood et al., 2018) and represents an interesting strategy for targeted recombination. In Arabidopsis, DNA is actively demethylated by ROS1 and related glycosylase enzymes through a base excision-repair process (Gong et al., 2002; Penterman et al., 2007; Zhu et al., 2007; Zhang and Zhu, 2012). An alternative pathway dependent on Ten-eleven translocation methylcytosine dioxygenase 1 (TET1) exists in human that biochemically removes DNA methylation. TET1 catalyzes the oxidation of 5 -methylcytosine $(5 \mathrm{mC})$ to 5 -hydroxymethylcytosine which is the initial step for DNA demethylation (Wu and Zhang, 2017). Fusion of human TET1 to an artificial zing finger or to CRISPR/ dCas9 effectively demethylates DNA at targeted loci in Arabidopsis (Figure 2A; Gallego-Bartolome et al., 2018). This method could in theory be used in conjunction with CRISPR/dCAS9 fused with SPO11 or a component of the DSB machinery to promote DSB formation in an otherwise cold region (Figure 2A).

The recruitment of SPO11 protein to a specific locus does not necessary ensure the formation of a DSB (even less so a CO-prone DSB). To form a DSB, SPO11 requires not only to be part of a protein complex but also to be functionally active (Robine et al., 2007; Sarno et al., 2017). Studies from budding yeast revealed that not every locus bound by SPO11-GAL4 is proficient to form DSBs, and the establishment of a DSB is determined by local factors (Robine et al., 2007; Sarno et al., 2017). In plants, a recent study suggests that expression of a MTOPVIB-dCas9 fusion protein to induce targeted meiotic DSB within a $\mathrm{CO}$ hotspot located in a subtelomeric region of chromosome 3 is not sufficient to affect CO frequency (Yelina et al., 2021). In budding yeast, it is estimated that around $40 \%$ of the DSBs are converted to COs (Mancera et al., 2008). In contrasts, in Arabidopsis (Ferdous et al., 2012), maize (Sidhu et al., 2015), and barley (Higgins et al., 2012) only about $2-5 \%$ of the DSB rate accounts for the total CO number and it is likely that the targeted DSBs will convert to COs at low frequency. In addition, a budding yeast study showed that expression of 

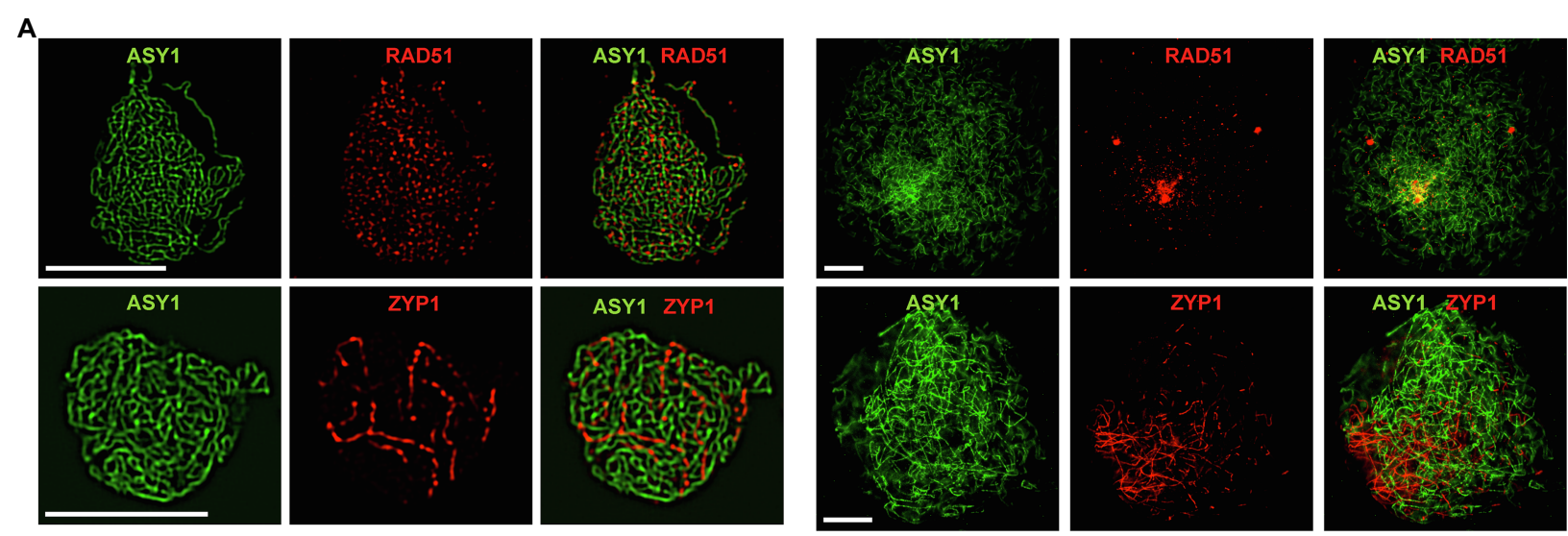

B

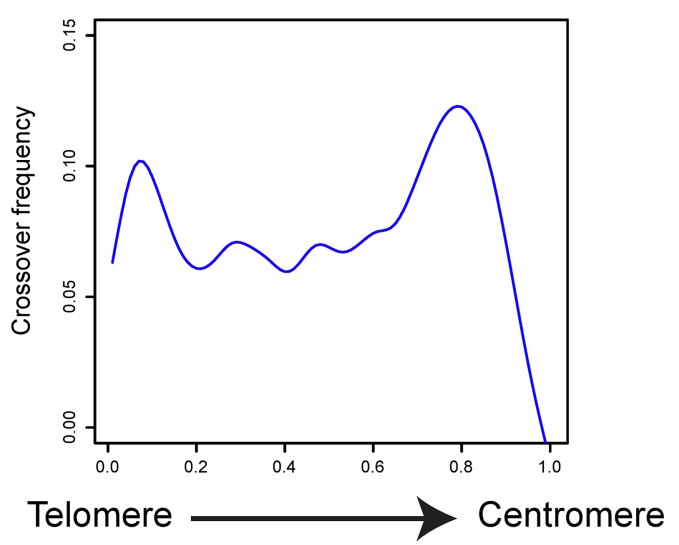

C Arabidopsis

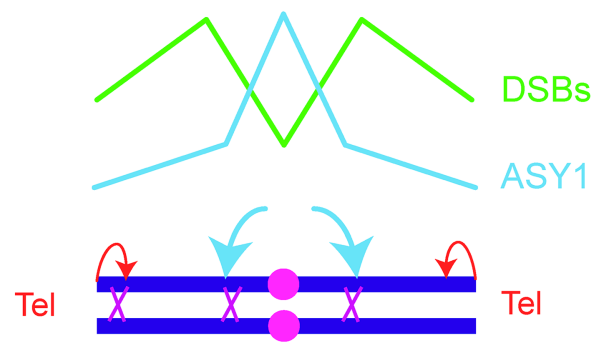

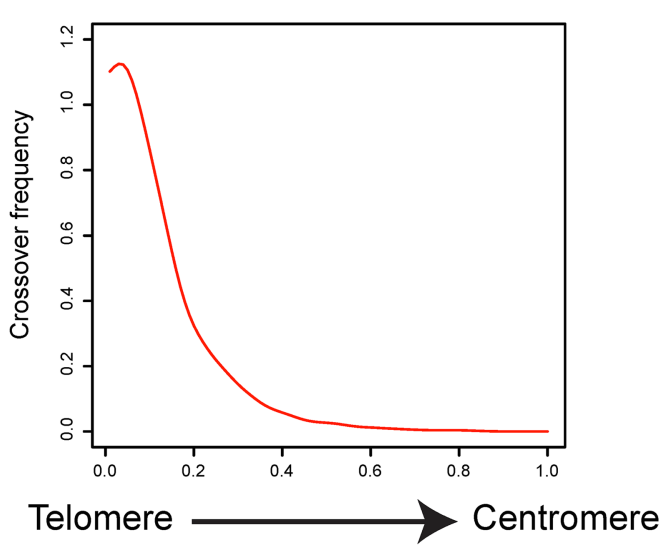

Barley/Wheat

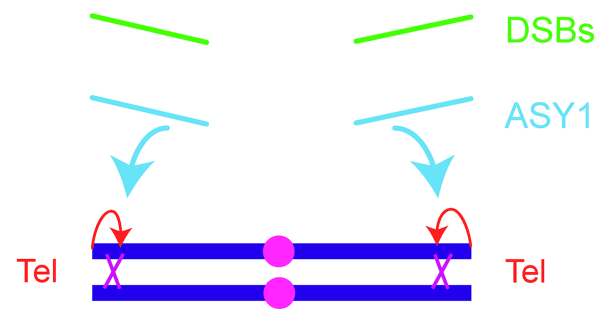

FIGURE 1 | Crossover patterning in Arabidopsis and cereals. (A) Co-immunostaining of ASY1 (green) and RAD51 (red) at leptotene or ASY1 (green) and ZYP1 (red) at zygotene in Arabidopsis (left panel) and hexaploid bread wheat Triticum aestivum cv. Cadenza (right panel; provided by Kim Osman, University of Birmingham, United Kingdom). Scale bar $=10 \mu \mathrm{m}$. (B) Crossover frequency along an axis from telomere to centromere in Arabidopsis (blue, left panel; replotted using the CO data of all chromosomes from Serra et al., 2018) and barley (red, right panel; CO data of all chromosomes provided by Mikel Arrieta, The James Hutton Institute, United Kingdom). (C) Two forces influence the crossover landscape: telomere-led recombination (red arrows) and ASY1 (cyan arrows). In leptotene, axis and DSBs are formed along the chromosomes at a similar time but in distinct levels in Arabidopsis (left panel). In contrast, axis and DSBs are formed first toward the distal end of the chromosomes in barley and wheat at leptotene (right panel). This difference in the spatio-temporal formation of axis and DSBs is associated with a different landscape of crossovers between Arabidopsis and barley/wheat. Pink filled circles represent centromeres, dark blue lines represent homologous chromosomes, and purple crosses represent crossovers. The landscape of ASY1 enrichment (cyan) and DSB frequency (green) in early prophase I are represented with solid lines.

SPO11-GAL4 in a spo11 null mutant forms DSBs at GAL4 sites but also at natural sites (Pecina et al., 2002). If conserved in plants, this propensity of SPO11 may further reduce the targeted effect. Moreover, barley and wheat chromosome axes initiate first in distal regions in early prophase (Higgins et al., 2012; Osman et al., 2021). It is unknown whether SPO11 is functionally active to form a DSB without a chromosome axis when recruited in centromere-proximal regions at an early stage of meiosis. 
A
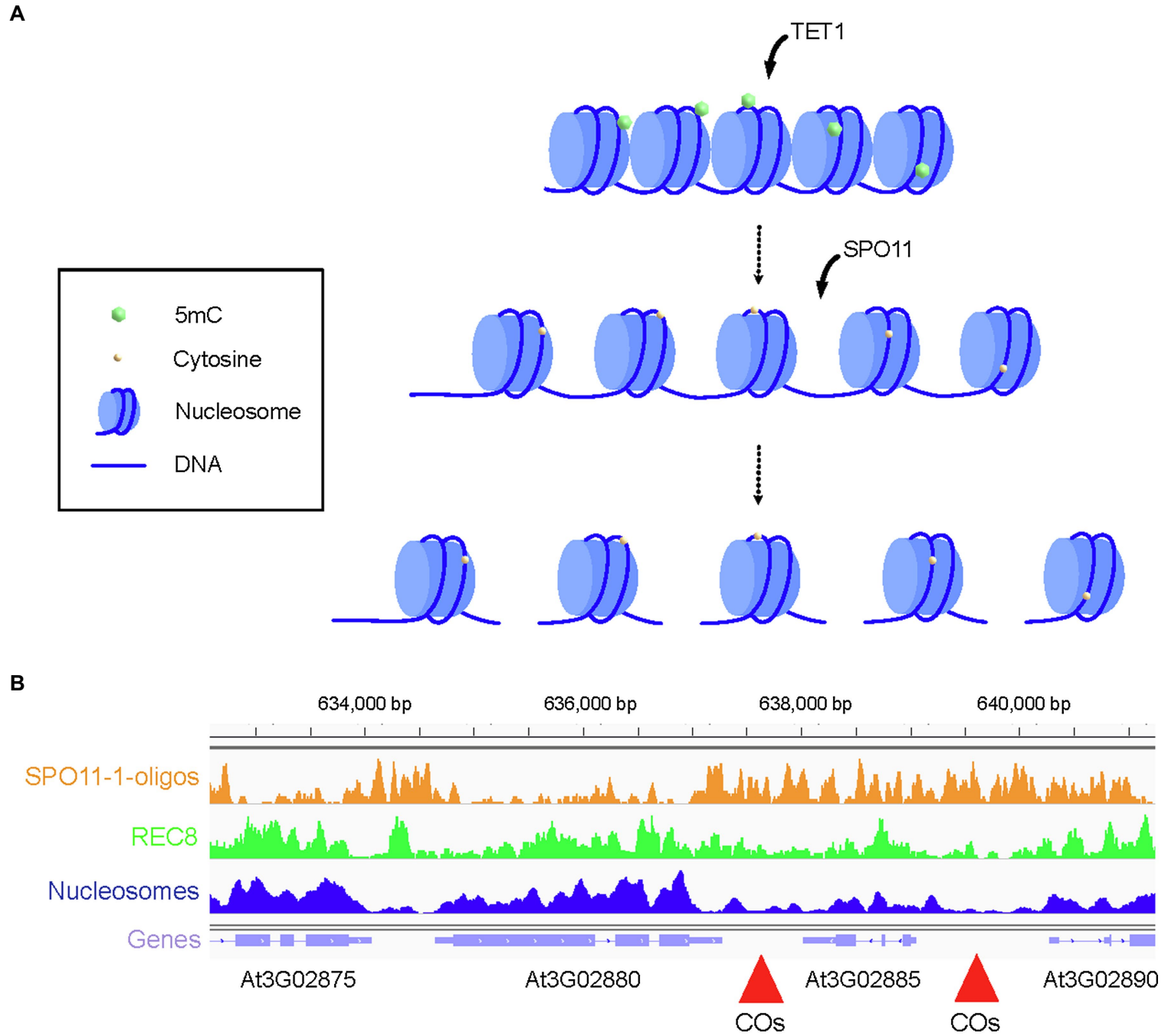

FIGURE 2 | Strategies to remodel the crossover rate locally. (A) Representation of a cold spot region enriched in nucleosome and silencing epigenetic marks, such as DNA methylation in all three contexts (CG, $\mathrm{CHG}$, and $\mathrm{CHH})$. Chromatin is methylated on $5 \mathrm{mCs}$. Targeted recruitment of TET1 catalyzes the removal of silencing epigenetic marks and decompaction of chromatin while the targeted recruitment of SPO11 catalyzes formation of DSBs. Meiotic DSBs are repaired by the homologous recombination pathway leading to the formation of NCO, NCO with gene conversion, or CO. (B) Genome browser view of the crossover hotspot $3 a$ on chromosome 3 of Arabidopsis. SPO11-1-oligo (orange), REC8 ChIP-seq (green), and nucleosome (MNase, dark blue) profiles are shown alongside the gene organization (purple). Regions with high crossover rate are indicated with red arrowheads. Coordinates on the chromosome 3 are shown above the genome browser view.

The induction of targeted recombination can have undesirable effects on recombination elsewhere in the genome. For example, the formation of DSBs at targeted sites inhibits the formation of DSBs in adjacent natural sites in budding yeast (Robine et al., 2007). Moreover, if the targeted DSB is converted to a $\mathrm{CO}$ this will inhibit the formation of a second $\mathrm{CO}$ in the adjacent regions via a phenomenon called $\mathrm{CO}$ interference (Berchowitz and Copenhaver, 2010). In Arabidopsis, the effect of $\mathrm{CO}$ interference is detected over $8-10 \mathrm{Mb}$ of DNA and the formation of a targeted $\mathrm{CO}$ will likely remodel the recombination landscape on that chromosome (Serra et al., 2018). Unlike COs, gene conversions have relatively short length $(<2 \mathrm{~kb})$ and are detected in most parts of the genome including across centromeric regions in plants (Shi et al., 2010). This type of recombination events is interesting because it only modifies the DNA sequence locally and does not seem to be under the same controls as COs (Shi et al., 2010). Moreover, targeted gene conversion events are unlikely to modify the broad CO landscape (Berchowitz and Copenhaver, 2010). This outcome is particularly interesting for plant breeding where targeted recombination is required to increase allelic diversity locally, such as in heterochromatic regions.

\section{CHROMOSOME ENGINEERING TO INFLUENCE MEIOTIC RECOMBINATION}

\section{Chromosome Structure and Crossovers}

Chromosome structure is also a strong determinant of CO formation and localization (Rowan et al., 2019). Chromosomal rearrangements, 
such as inversions or translocations, usually suppress recombination, and this is particularly challenging for breeding since they may inhibit the transfer of important traits between different plant cultivars. Indeed, a number of inversions and translocations can be detected by comparing the genomic sequences between accessions (Zapata et al., 2016). Recently, somatic chromosomal engineering using CRISPR/Cas9 has proven useful for restoring recombination in naturally rearranged chromosomal regions in Arabidopsis (Schmidt et al., 2020). A particularly well-known case of inversion in Arabidopsis is the heterochromatic knob on chromosome 4 (Fransz et al., 2000). When an Arabidopsis accession carrying this inversion is crossed with an accession without inverted knob, $\mathrm{CO}$ formation within the entire rearranged region is suppressed (Schmidt et al., 2020). The authors developed an egg cell-specific expression system of the Cas 9 nuclease that allows rearranging the structure of plant chromosomes in a targeted and heritable manner (Beying et al., 2020; Schmidt et al., 2020). Remarkably, reversion of the $1.1 \mathrm{Mb}$ heterochromatic knob on chromosome 4 fully restored $\mathrm{CO}$ formation in this region (Schmidt et al., 2020). This is a particularly promising achievement for breeding given that many crop plants have experienced substantial chromosomal rearrangements that strongly affect CO formation.

\section{Effect of Ploidy Manipulation on Crossovers}

Interestingly, a link between increased ploidy level and crossover formation has been demonstrated in a number of plants (reviewed in Pele et al., 2017). For instance, in Arabidopsis, analyses of CO formation in one genetic interval show that both male and female $\mathrm{CO}$ frequencies are significantly higher in newly formed auto- and allopolyploids compared to their diploid progenitors (Pecinka et al., 2011). Additionally, studies in Brassica demonstrated that Brassica allotriploid hybrids exhibit a significant crossover increase compare to their progenitors (Leflon et al., 2010; Suay et al., 2014; Pele et al., 2017). This increase occurs genome wide and affects both male and female meiosis, although stronger increase is observed in female and is associated with a significant remodeling of the CO landscape with the presence of COs in the vicinity of centromeres. Remarkably, this increase is also accompanied by a strong decrease in CO interference (Suay et al., 2014; Pele et al., 2017). Although the underlying mechanism remains to be demonstrated, it appears that the link between ploidy level and CO increase is associated with genetic content. Indeed, further work in Brassica has shown that the addition of one specific chromosome ( $\mathrm{C}$ genome chromosome 9) is sufficient to increase $\mathrm{CO}$ in polyploid hybrids while addition of other chromosomes had no effect (Suay et al., 2014). Altogether, these results suggest that manipulating ploidy level and/or chromosome composition may be a promising alternative for plant breeders to modulate $\mathrm{CO}$ formation and ultimately increase genetic diversity of crop plants.

\section{HOW CAN WE REMODEL MEIOSIS FOR CROP IMPROVEMENT?}

The manipulation of meiotic recombination gives the breeders a tool to create a new and desirable allele of gene that could be incorporated to a germ line and, unlike the product of mitotic recombination, this trait will be carried to the whole plant as it develops. However, such trait can be removed/ modified as meiotic recombination continuously occurs in the following generations. Moreover, the process of meiosis maintains the ploidy of the progeny and limits cross-breeding between accessions or related species containing different ploidy. To overcome these constraints for crop breeding, the meiotic division processes could be engineered to adapt the need of a breeding program.

\section{Diploid Gametes}

An important application for remodeling the meiotic division process is to allow formation of unreduced gametes (Figure 3). Indeed, a major function of meiosis is to reduce the chromosome complement by half with two successive divisions following a single round of DNA replication. Consequently, circumvention of one division allows formation of unreduced gametes which have proved useful for breeding. Specifically, unreduced gametes are used by breeders to engineer sexual polyploidization (Brownfield and Kohler, 2011; Crismani and Mercier, 2012; De Storme and Geelen, 2013; Ronceret and Vielle-Calzada, 2015). They can facilitate crosses between plants with different ploidy levels or to be utilized to create new polyploid species exhibiting increased genetic diversity and hybrid vigor. It has long been considered that formation of diploid gametes is, at least in part, genetically controlled. Accordingly, a number of mutants producing diploid gametes have been identified in various plants (for reviews see Brownfield and Kohler, 2011; Crismani and Mercier, 2012; De Storme and Geelen, 2013; Ronceret and Vielle-Calzada, 2015). These mutants are usually classified as first division restitution (FDR) or second division restitution (SDR) depending on whether the mutations affect the first or second division, respectively (Figures $3 \mathbf{A}-\mathbf{C}$ ). In Arabidopsis, notable examples of these are mutations in parallelspindle 1 or Jason that both lead to FDR through disturbance of spindle orientation and positioning (D'Erfurth et al., 2008; De Storme and Geelen, 2011). On the contrary, SDR has been obtained by mutating genes controlling entry into second division, such as OMISSION OF DIVISION 1 (OSD1) a key regulator of the anaphase promoting complex, or the cyclin CYCA1;2/TARDY ASYNCHRONOUS MEIOSIS (TAM1; D'Erfurth et al., 2009, 2010). A key difference between FDR and SDR is that they lead to different genetic outcomes. FDR-influenced chromosomes are non-sister chromatids, and therefore, FDR is often considered to produce unreduced gametes with enriched heterozygous marker genotypes (from centromeres to first crossover sites). On the contrary, in SDR, affected chromosomes are sister chromatids (second division not occurring) and the unreduced gametes exhibit homozygous marker genotypes from the centromeres to the first crossover site. Hence, it is important to take into account the desired level of heterozygosity when considering FDR or SDR for a breeding strategy. Interestingly, diploid gametes may also be obtained by applying external stimuli. For example, a high number of diploid gametes are produced when haploid Arabidopsis plants are treated with a $4^{\circ} \mathrm{C}$ cold shock for several 
A

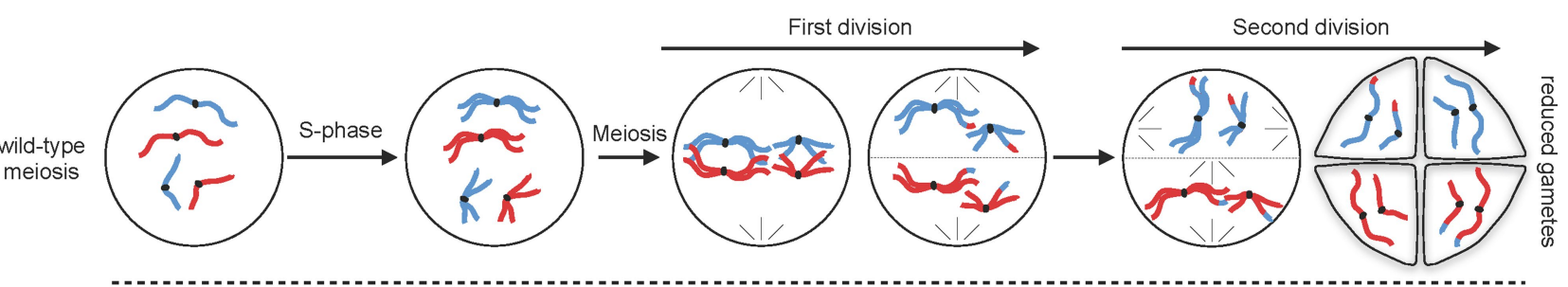

B

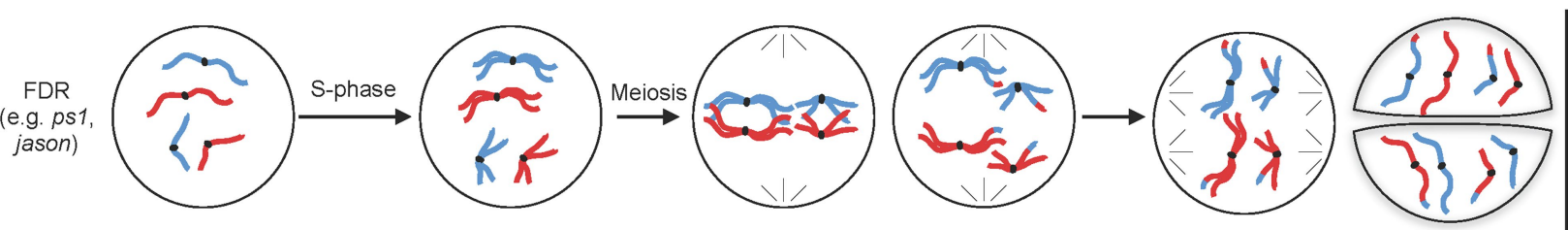

C

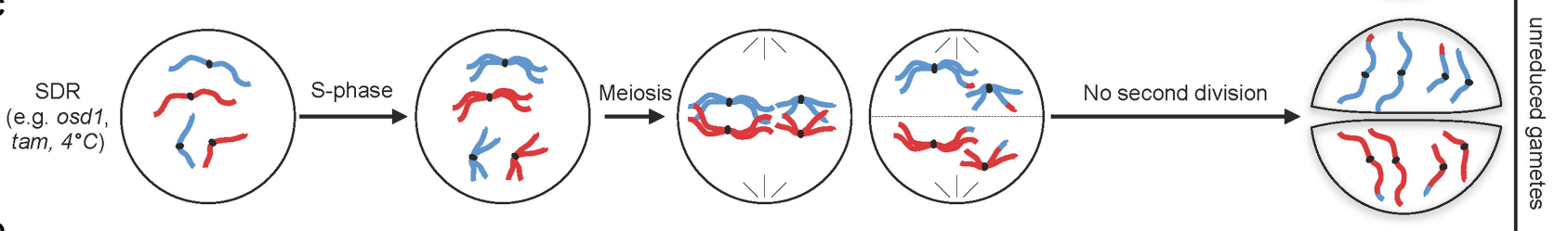

D

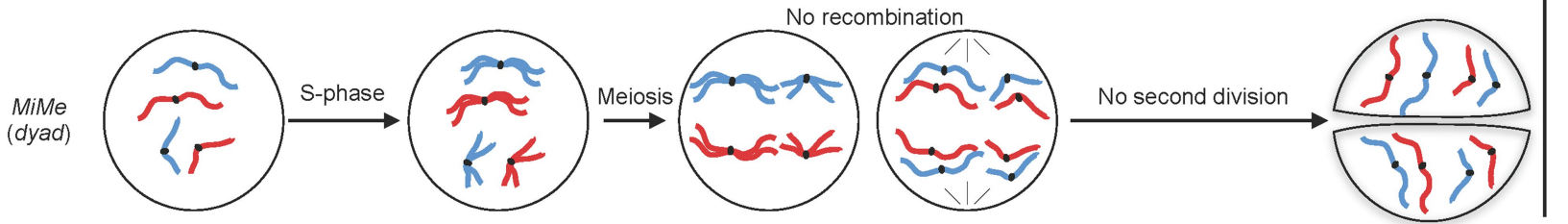

E

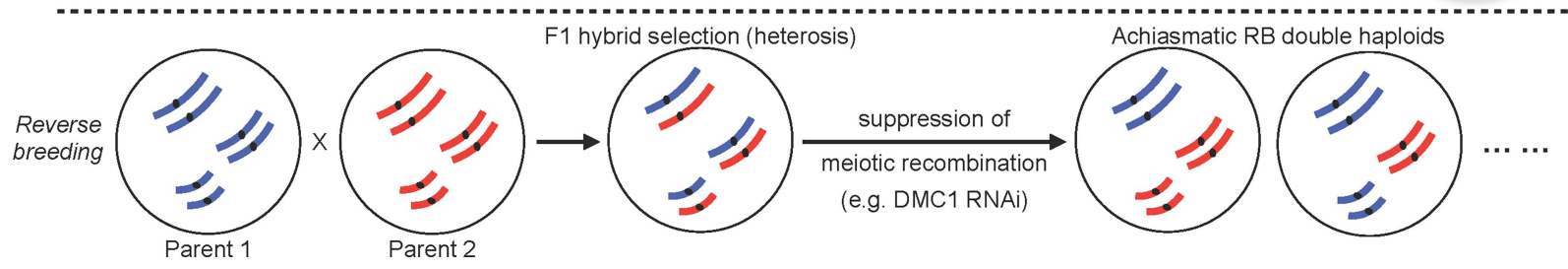

FIGURE 3 | Schematic representation of different strategies to remodel the meiotic division. (A) Normal meiotic division resulting in haploid (n) gametes. (B,C) Nonreductional meiotic divisions resulting in unreduced (2n) meiotic products. First division restitution (FDR; B) and second division restitution (SDR; C) lead to different levels of heterozygosity (see text for details). (D) Schematic diagram of apomeiosis obtained through MiMe strategy. (E) Reverse breeding strategy. For simplification, in each case, a diploid cell with only two chromosome pairs is shown with maternal and paternal chromosomes in red and blue, respectively.

hours during flowering stage and this process primarily undergoes SDR (De Storme and Geelen, 2011). Whether this strategy is effective in crops and if other stimuli may trigger similar effects are not yet known. Nevertheless, such approach may be highly relevant for breeding since it would be classified as non-transgenic.

\section{Apomeiosis}

Both FDR and SDR result in unreduced gametes which contains chromosomes that were recombined via meiotic recombination. However, regarding to breeding strategies, unreduced gametes that have retained parental genome are more useful. Apomixis, in particular, is a form of asexual reproduction allowing clonal reproduction through seeds (Spillane et al., 2004). Apomixis produces progenies that are genetically identical to the maternal genome. This is especially beneficial on the breeding of hybrid varieties since it allows fixation of an elite hybrid genome and its clonal propagation through seeds. Although apomixis naturally occurs in a number of angiosperms, it is absent in most important crops (Spillane et al., 2004). Its success relies on the circumvention of both meiosis and fertilization. A cornerstone of apomixis is thus apomeiosis, a deregulated form of meiosis resulting in a mitotic-like division that prevents recombination and ploidy reduction. Several single mutants disrupting the meiotic process and leading to apomeiosis have been identified in Arabidopsis, rice, and maize (Ronceret and Vielle-Calzada, 2015; Figure 3D). However, these mutants are usually sterile and form apomeiotic gametes at an extremely low frequency. The best example of these is the Arabidopsis DYAD/SWITCH1 gene, a regulator of meiotic chromosome organizations essential for meiotic entry (Ravi et al., 2008). Artificial apomeiosis has been successfully achieved through mutation of this single gene (Ravi et al., 2008). In the dyad allele, alteration of the meiotic process into a mitotic-like division leads to the formation of unreduced female gametes that retain parental heterozygosity, representative of apomeiosis. However, although this appeared 
promising at first sight, it is hardly amenable to crops since dyad plants are nearly sterile and less than $1 \%$ of the dyad ovules generate viable gametes (Ravi et al., 2008).

Rather than mutating a single gene, a major success in engineering apomeiosis was later obtained by combining several mutations that disrupt the key steps of the meiotic division (D'Erfurth et al., 2009; Figure 3D). This was accomplished by simultaneously disrupting three key steps of meiosis: (1) bypassing of the second meiotic division to allow production of functional diploid gametes; this can be achieved through mutating and removing the function of the key regulator OSD1, (2) suppression of meiotic recombination to prevent formation of recombined gametes. This can be achieved through mutation of genes involved in meiotic DSB formation. For example, using a null allele of SPO11-1 to eliminate the initiation of meiotic DSB formation, and (3) allowing segregation of sister chromatids at the first division through loss-of-function of the meiotic-specific cohesin REC8. In Arabidopsis, plants with this genotype undergo meiosis that is replaced by mitosis and they are called MiMe (for Mitosis instead of Meiosis). This remodeling of meiosis gives rise to functional diploid gametes with genetically identical genomes (D'Erfurth et al., 2009; Figure 3D). The practicability of this technology was further demonstrated by alternatively targeting other genes disrupting the key steps of meiosis. For instance, the use of osd 1 mutation to bypass the second meiotic segregation has been successfully replaced by mutation of the cyclin CYCA1;2/TAM1 or use of a $t d m 1$ dominant mutation (D'Erfurth et al., 2010; Cifuentes et al., 2016). Similarly, suppression of meiotic recombination can be obtained by mutating various components of the meiotic DSB complex (e.g., PRD1, PRD2, or PRD3; Mieulet et al., 2016). This artificial engineering of apomeiosis is a particularly ground-breaking achievement since MiMe plants are fertile and produce near wild-type levels of viable apomeiotic gametes. Remarkably, this technology has also recently been translated to rice (Mieulet et al., 2016). Through mutation of rice OSD1, PAIR1 (rice homolog of PRD3), and REC8, the authors could reproduce the $M i M e$ genotype and, importantly, showed that rice $M i M e$ plants remained fertile. Altogether these data demonstrate the potential of the MiMe technology for engineering apomeiosis in plants. Yet, it remains unclear whether this technology is applicable to other crops and, in particular, polyploid species, such as bread wheat. Another obstacle of this technology is that since gametes are diploid and normal fertilization continues to occur, ploidy is expected to double at each generation. To overcome this problem, MiMe technology has been combined with genome elimination strategies that allow removal of a complete set of chromosome from one parent after fertilization (Ishii et al., 2016; Jacquier et al., 2020). Such genome elimination is usually accomplished by using haploid inducer lines which can be obtained through manipulation of the centromeric histone 3 variant (CENH3; Ravi et al., 2008; Marimuthu et al., 2011), or the MATRILINEAL/NOT-LIKE DAD/PHOSPHOLIPASE A1 gene (Wang et al., 2019a). Haploid inducer lines do not directly affect meiosis and will thus not be described here. For detailed description of haploid inducer lines and genome elimination, readers are directed to several excellent recent reviews (Ishii et al., 2016; Jacquier et al., 2020). Alternatively, creation of haploid plants can also be obtained by misexpression in egg cell of the $B A B Y B O O M 1$ (BBM1) gene (Khanday et al., 2019). $B B M 1$ is a male-expressed gene essential to initiate embryogenesis after fertilization and misexpression of $B B M 1$ in egg cell is sufficient to trigger parthenogenesis and the production of haploid plants (Khanday et al., 2019). Remarkably, combining one of these strategies with MiMe technology has allowed engineering clonal reproduction in both Arabidopsis and rice (Marimuthu et al., 2011; Khanday et al., 2019; Wang et al., 2019a; Khanday and Sundaresan, 2021). Yet, frequencies of clonal embryo remain low (haploid inducer lines are not fully penetrant) and overall seed production is also strongly decreased. This means that broad implementation of apomixis in a sustainable way in crops will require further research to unravel new factors and mechanisms controlling apomeiosis and haploid induction. However, to achieve this will also require a better understanding of the interplay between these two components of apomixis.

\section{Reverse Breeding}

Heterozygous hybrids have the tendency to outperform their homozygous parents in fitness (Chen, 2010; Labroo et al., 2021). This phenomenon, known as hybrid vigor or heterosis, is widely used by breeders to produce elite varieties with improved field quality. Creation of these elite heterozygous hybrids is achieved by crossing two selected homozygous parents. However, such favorable hybrids cannot be stably maintained because allele combinations are reshuffled by genetic recombination during meiosis before being transmitted to the progeny. This means that offspring lose the heterosis effect and breeders must continuously recreate favorable hybrids. Different strategies have been proposed to preserve transmission of heterozygous genotypes. Reverse breeding, which is an alternative to apomixis, has emerged as a promising strategy to fix hybrid genomes (Dirks et al., 2009; Figure 3E). Reverse breeding generates homozygous parental lines from a heterozygous hybrid. When applied to hybrids with known parents, the approach can also be used to generate chromosome substitution lines, in which the chromosome of one line is replaced by the chromosome of another line (Dirks et al., 2009). The method relies on suppression of meiotic crossovers in the hybrid followed by the production of doubled haploids from non-recombinant gametes (Dirks et al., 2009; Figure 3E). The practicability of the method was originally demonstrated in Arabidopsis by silencing the meiotic-specific recombinase DMC1 using RNA interference (Wijnker et al., 2012, 2014). Non-recombinant gametes were converted into haploid adult plants using centromere-mediated genome elimination and fertile diploids (double haploids) and were eventually obtained by self-pollination of those haploids (Wijnker et al., 2012). The main limitation of the method lies in the fact that suppression of meiotic recombination leads to achiasmatic chromosomes which segregate randomly. Production of balanced non-recombinant gametes thus relies on fortuitous balanced 
segregation, whose frequency strongly depends on chromosome number. The method is thus limited to species with low chromosome number (less than 12; Dirks et al., 2009). An alternative to the solution would be to reduce, but not completely suppress, CO formation. Having one or a few CO would still lead to low production of $\mathrm{CO}$-free gametes but will also increase the production of gametes with low $\mathrm{CO}$ numbers, which would prove useful for reverse breeding. This strategy was recently validated by downregulating Arabidopsis $\mathrm{MSH} 5$ gene expression through VIGS (Calvo-Baltanas et al., 2020). Furthermore, VIGS has the additional advantage of allowing transient downregulation and thus avoids integration of a stable transgene in the genome, which is a strong concern for breeders. Altogether, these data suggest that reverse breeding could be effectively applied to many crops. However, unlike apomixis, this strategy has not yet been demonstrated in crops.

\section{CONCLUDING REMARKS}

Several novel insights on meiosis have emerged in recent years and form a framework to develop innovative technologies to accelerate pre-breeding strategies. However, most of our understanding of meiosis is based on Arabidopsis research and it is of particular importance to pivot toward the translational

\section{REFERENCES}

Acquaviva, L., Szekvolgyi, L., Dichtl, B., Dichtl, B. S., De La Roche Saint Andre, C., Nicolas, A., et al. (2013). The COMPASS subunit Spp1 links histone methylation to initiation of meiotic recombination. Science 339, 215-218. doi: 10.1126/science.1225739

Armstrong, S. J., Caryl, A. P., Jones, G. H., and Franklin, F. C. (2002). Asyl, a protein required for meiotic chromosome synapsis, localizes to axis-associated chromatin in Arabidopsis and brassica. J. Cell Sci. 115, 3645-3655. doi: $10.1242 /$ jcs. 00048

Armstrong, S. J., Franklin, F. C., and Jones, G. H. (2001). Nucleolus-associated telomere clustering and pairing precede meiotic chromosome synapsis in Arabidopsis thaliana. J. Cell Sci. 114, 4207-4217. doi: 10.1242/jcs.114.23.4207

Barakate, A., Higgins, J. D., Vivera, S., Stephens, J., Perry, R. M., Ramsay, L., et al. (2014). The synaptonemal complex protein ZYP1 is required for imposition of meiotic crossovers in barley. Plant Cell 26, 729-740. doi: $10.1105 /$ tpc. 113.121269

Benyahya, F., Nadaud, I., Da Ines, O., Rimbert, H., White, C., and Sourdille, P. (2020). SPO11.2 is essential for programmed double-strand break formation during meiosis in bread wheat (Triticum aestivum L.). Plant J. 104, 30-43. doi: $10.1111 /$ tpj. 14903

Berchowitz, L. E., and Copenhaver, G. P. (2010). Genetic interference: don't stand so close to me. Curr. Genomics 11, 91-102. doi: 10.2174/138920210790886835

Bergerat, A., De Massy, B., Gadelle, D., Varoutas, P. C., Nicolas, A., and Forterre, P. (1997). An atypical topoisomerase II from archaea with implications for meiotic recombination. Nature 386, 414-417. doi: 10.1038/386414a0

Beying, N., Schmidt, C., Pacher, M., Houben, A., and Puchta, H. (2020). CRISPR-Cas9-mediated induction of heritable chromosomal translocations in Arabidopsis. Nat. Plants 6, 638-645. doi: 10.1038/s41477-020-0663-x

Blackwell, A. R., Dluzewska, J., Szymanska-Lejman, M., Desjardins, S., Tock, A. J., Kbiri, N., et al. (2020). MSH2 shapes the meiotic crossover landscape in relation to interhomolog polymorphism in Arabidopsis. EMBO J. 39:e104858. doi: $10.15252 / \mathrm{embj} .2020104858$

Blary, A., Gonzalo, A., Eber, F., Berard, A., Berges, H., Bessoltane, N., et al. (2018). FANCM limits meiotic crossovers in brassica crops. Front. Plant Sci. 9:368. doi: $10.3389 /$ fpls.2018.00368 potential of these discoveries and the study of other plant species. It is likely that future studies will identify significant differences in the regulation of meiosis between Arabidopsis and crops which may occlude a direct transfer of certain strategies between plants. Comparative studies of meiosis across a broad range of species will address this gap in our knowledge and have the potential to identify new functional pathways and to provide a deeper understanding of the evolution of meiotic gene function.

\section{AUTHOR CONTRIBUTIONS}

All authors listed have made a substantial, direct and intellectual contribution to the work, and approved it for publication.

\section{ACKNOWLEDGMENTS}

We would like to thank Dr. Kim Osman for providing the images of wheat chromosome staining and Dr. Mikel Arrieta and the James Hutton Institute for providing the crossover frequency data in Barley. We would also like to thank Dr. Charles White and Dr. Alexander Blackwell for their comments on the manuscript.

Brownfield, L., and Kohler, C. (2011). Unreduced gamete formation in plants: mechanisms and prospects. J. Exp. Bot. 62, 1659-1668. doi: 10.1093/jxb/ erq371

Cai, X., Dong, F., Edelmann, R. E., and Makaroff, C. A. (2003). The Arabidopsis SYN1 cohesin protein is required for sister chromatid arm cohesion and homologous chromosome pairing. J. Cell Sci. 116, 2999-3007. doi: 10.1242/ jcs.00601

Calvo-Baltanas, V., Wijnen, C. L., Yang, C., Lukhovitskaya, N., De Snoo, C. B., Hohenwarter, L., et al. (2020). Meiotic crossover reduction by virus-induced gene silencing enables the efficient generation of chromosome substitution lines and reverse breeding in Arabidopsis thaliana. Plant J. 104, 1437-1452. doi: $10.1111 /$ tpj.14990

Capilla-Perez, L., Durand, S., Hurel, A., Lian, Q., Chambon, A., Taochy, C., et al. (2021). The synaptonemal complex imposes crossover interference and heterochiasmy in Arabidopsis. Proc. Natl. Acad. Sci. U. S. A. 118:e2023613118. doi: 10.1073/pnas.2023613118

Chambon, A., West, A., Vezon, D., Horlow, C., De Muyt, A., Chelysheva, L., et al. (2018). Identification of ASYNAPTIC4, a component of the meiotic chromosome axis. Plant Physiol. 178, 233-246. doi: 10.1104/pp.17.01725

Chelysheva, L., Diallo, S., Vezon, D., Gendrot, G., Vrielynck, N., Belcram, K., et al. (2005). AtREC8 and AtSCC3 are essential to the monopolar orientation of the kinetochores during meiosis. J. Cell Sci. 118, 4621-4632. doi: 10.1242/ jcs. 02583

Chen, Z. J. (2010). Molecular mechanisms of polyploidy and hybrid vigor. Trends Plant Sci. 15, 57-71. doi: 10.1016/j.tplants.2009.12.003

Chen, X., Suhandynata, R. T., Sandhu, R., Rockmill, B., Mohibullah, N., Niu, H., et al. (2015). Phosphorylation of the synaptonemal complex protein zip1 regulates the crossover/noncrossover decision during yeast meiosis. PLoS Biol. 13:e1002329. doi: 10.1371/journal.pbio.1002329

Choi, K., Zhao, X., Tock, A. J., Lambing, C., Underwood, C. J., Hardcastle, T. J., et al. (2018). Nucleosomes and DNA methylation shape meiotic DSB frequency in Arabidopsis thaliana transposons and gene regulatory regions. Genome Res. 28, 532-546. doi: 10.1101/gr.225599.117

Cifuentes, M., Jolivet, S., Cromer, L., Harashima, H., Bulankova, P., Renne, C., et al. (2016). TDM1 regulation determines the number of meiotic divisions. PLoS Genet. 12:e1005856. doi: 10.1371/journal.pgen.1005856 
Cloud, V., Chan, Y. L., Grubb, J., Budke, B., and Bishop, D. K. (2012). Rad51 is an accessory factor for Dmc1-mediated joint molecule formation during meiosis. Science 337, 1222-1225. doi: 10.1126/science.1219379

Corem, S., Doron-Faigenboim, A., Jouffroy, O., Maumus, F., Arazi, T., and Bouche, N. (2018). Redistribution of CHH methylation and small interfering RNAs across the genome of tomato ddm1 mutants. Plant Cell 30, 1628-1644. doi: $10.1105 /$ tpc. 18.00167

Coulton, A., Burridge, A. J., and Edwards, K. J. (2020). Examining the effects of temperature on recombination in wheat. Front. Plant Sci. 11:230. doi: 10.3389/fpls.2020.00230

Crismani, W., Girard, C., Froger, N., Pradillo, M., Santos, J. L., Chelysheva, L., et al. (2012). FANCM limits meiotic crossovers. Science 336, 1588-1590. doi: $10.1126 /$ science. 1220381

Crismani, W., and Mercier, R. (2012). What limits meiotic crossovers? Cell Cycle 11, 3527-3528. doi: 10.4161/cc.21963

Da Ines, O., Abe, K., Goubely, C., Gallego, M. E., and White, C. I. (2012). Differing requirements for RAD51 and DMC1 in meiotic pairing of centromeres and chromosome arms in Arabidopsis thaliana. PLoS Genet. 8:e1002636. doi: 10.1371/journal.pgen.1002636

Da Ines, O., Michard, R., Fayos, I., Bastianelli, G., Nicolas, A., Guiderdoni, E., et al. (2020). Bread wheat TaSPO11-1 exhibits evolutionarily conserved function in meiotic recombination across distant plant species. Plant J. 103, 2052-2068. doi: 10.1111/tpj.14882

Da Ines, O., and White, C. I. (2015). Centromere associations in meiotic chromosome pairing. Annu. Rev. Genet. 49, 95-114. doi: 10.1146/annurevgenet-112414-055107

De Maagd, R. A., Loonen, A., Chouaref, J., Pele, A., Meijer-Dekens, F., Fransz, P., et al. (2020). CRISPR/Cas inactivation of RECQ4 increases homeologous crossovers in an interspecific tomato hybrid. Plant Biotechnol. J. 18, 805-813. doi: $10.1111 /$ pbi.13248

De Muyt, A., Pereira, L., Vezon, D., Chelysheva, L., Gendrot, G., Chambon, A., et al. (2009). A high throughput genetic screen identifies new early meiotic recombination functions in Arabidopsis thaliana. PLoS Gent. 5:e1000654. doi: 10.1371/journal.pgen.1000654

De Muyt, A., Vezon, D., Gendrot, G., Gallois, J.-L., Stevens, R., and Grelon, M. (2007). AtPRD1 is required for meiotic double strand break formation in Arabidopsis thaliana. EMBO J. 26, 4126-4137. doi: 10.1038/sj.emboj.7601815

De Storme, N., and Geelen, D. (2011). The Arabidopsis mutant jason produces unreduced first division restitution male gametes through a parallel/fused spindle mechanism in meiosis II. Plant Physiol. 155, 1403-1415. doi: 10.1104/ pp. 110.170415

De Storme, N., and Geelen, D. (2013). Sexual polyploidization in plants-cytological mechanisms and molecular regulation. New Phytol. 198, 670-684. doi: $10.1111 / \mathrm{nph} .12184$

D’Erfurth, I., Cromer, L., Jolivet, S., Girard, C., Horlow, C., Sun, Y., et al. (2010). The cyclin-A CYCA1;2/TAM is required for the meiosis I to meiosis II transition and cooperates with OSD1 for the prophase to first meiotic division transition. PLoS Genet. 6:e1000989. doi: 10.1371/journal.pgen.1000989

D’Erfurth, I., Jolivet, S., Froger, N., Catrice, O., Novatchkova, M., and Mercier, R. (2009). Turning meiosis into mitosis. PLoS Biol. 7:e1000124. doi: 10.1371/ journal.pbio.1000124

D’Erfurth, I., Jolivet, S., Froger, N., Catrice, O., Novatchkova, M., Simon, M., et al. (2008). Mutations in AtPS1 (Arabidopsis thaliana parallel spindle 1) lead to the production of diploid pollen grains. PLoS Genet. 4:e1000274. doi: 10.1371/journal.pgen.1000274

Desjardins, S. D., Ogle, D. E., Ayoub, M. A., Heckmann, S., Henderson, I. R., Edwards, K. J., et al. (2020). MutS homologue 4 and MutS homologue 5 maintain the obligate crossover in wheat despite stepwise gene loss following polyploidization. Plant Physiol. 183, 1545-1558. doi: 10.1104/pp.20.00534

Dirks, R., Van Dun, K., De Snoo, C. B., Van Den Berg, M., Lelivelt, C. L., Voermans, W., et al. (2009). Reverse breeding: a novel breeding approach based on engineered meiosis. Plant Biotechnol. J. 7, 837-845. doi: 10.1111/j. 1467-7652.2009.00450.x

Drouaud, J., Khademian, H., Giraut, L., Zanni, V., Bellalou, S., Henderson, I. R., et al. (2013). Contrasted patterns of crossover and non-crossover at Arabidopsis thaliana meiotic recombination hotspots. PLoS Genet. 9:e1003922. doi: 10.1371/ journal.pgen.1003922

Ellermeier, C., Higuchi, E. C., Phadnis, N., Holm, L., Geelhood, J. L., Thon, G., et al. (2010). RNAi and heterochromatin repress centromeric meiotic recombination. Proc. Natl. Acad. Sci. U. S. A. 107, 8701-8705. doi: 10.1073/ pnas.0914160107

Fayos, I., Meunier, A. C., Vernet, A., Navarro-Sanz, S., Portefaix, M., Lartaud, M., et al. (2020). Assessment of the roles of SPO11-2 and SPO11-4 in meiosis in rice using CRISPR/Cas9 mutagenesis. J. Exp. Bot. 71, 7046-7058. doi: 10.1093/jxb/eraa391

Ferdous, M., Higgins, J. D., Osman, K., Lambing, C., Roitinger, E., Mechtler, K., et al. (2012). Inter-homolog crossing-over and synapsis in Arabidopsis meiosis are dependent on the chromosome axis protein AtASY3. PLoS Genet. 8:e1002507. doi: 10.1371/journal.pgen.1002507

Fernandes, J. B., Seguela-Arnaud, M., Larcheveque, C., Lloyd, A. H., and Mercier, R. (2018). Unleashing meiotic crossovers in hybrid plants. Proc. Natl. Acad. Sci. U. S. A. 115, 2431-2436. doi: 10.1073/pnas.1713078114

Fernandes, J. B., Wlodzimierz, P., and Henderson, I. R. (2019). Meiotic recombination within plant centromeres. Curr. Opin. Plant Biol. 48, 26-35. doi: $10.1016 /$ j.pbi.2019.02.008

France, M. G., Enderle, J., Rohrig, S., Puchta, H., Franklin, F. C. H., and Higgins, J. D. (2021). ZYP1 is required for obligate cross-over formation and cross-over interference in Arabidopsis. Proc. Natl. Acad. Sci. U. S. A. 118:2021671118. doi: 10.1073/pnas.2021671118

Fransz, P. F., Armstrong, S., De Jong, J. H., Parnell, L. D., Van Drunen, C., Dean, C., et al. (2000). Integrated cytogenetic map of chromosome arm $4 \mathrm{~S}$ of A. thaliana: structural organization of heterochromatic knob and centromere region. Cell 100, 367-376. doi: 10.1016/S0092-8674(00)80672-8

Fu, M., Wang, C., Xue, F., Higgins, J., Chen, M., Zhang, D., et al. (2016). The DNA topoisomerase VI-B subunit OsMTOPVIB is essential for meiotic recombination initiation in rice. Mol. Plant 9, 1539-1541. doi: 10.1016/j. molp.2016.07.006

Gallego-Bartolome, J., Gardiner, J., Liu, W., Papikian, A., Ghoshal, B., Kuo, H. Y., et al. (2018). Targeted DNA demethylation of the Arabidopsis genome using the human TET1 catalytic domain. Proc. Natl. Acad. Sci. U. S. A. 115, E2125-E2134. doi: 10.1073/pnas.1716945115

Gardiner, L. J., Wingen, L. U., Bailey, P., Joynson, R., Brabbs, T., Wright, J., et al. (2019). Analysis of the recombination landscape of hexaploid bread wheat reveals genes controlling recombination and gene conversion frequency. Genome Biol. 20:69. doi: 10.1186/s13059-019-1675-6

Girard, C., Chelysheva, L., Choinard, S., Froger, N., Macaisne, N., Lemhemdi, A., et al. (2015). AAA-ATPase FIDGETIN-LIKE 1 and helicase FANCM antagonize meiotic crossovers by distinct mechanisms. PLoS Genet. 11:e1005369. doi: 10.1371/journal.pgen.1005448

Golubovskaya, I. N., Hamant, O., Timofejeva, L., Wang, C. J., Braun, D., Meeley, R., et al. (2006). Alleles of afd1 dissect REC8 functions during meiotic prophase I. J. Cell Sci. 119, 3306-3315. doi: 10.1242/jcs.03054

Gong, Z., Morales-Ruiz, T., Ariza, R. R., Roldan-Arjona, T., David, L., and Zhu, J. K. (2002). ROS1, a repressor of transcriptional gene silencing in Arabidopsis, encodes a DNA glycosylase/lyase. Cell 111, 803-814. doi: 10.1016/ S0092-8674(02)01133-9

Hartung, F., Wurz-Wildersinn, R., Fuchs, J., Schubert, I., Suer, S., and Puchta, H. (2007). The catalytically active tyrosine residues of both SPO11-1 and SPO11-2 are required for meiotic double-strand break induction in Arabidopsis. Plant Cell 19, 3090-3099. doi: 10.1105/tpc.107.054817

He, Y., Wang, M., Dukowic-Schulze, S., Zhou, A., Tiang, C. L., Shilo, S., et al. (2017). Genomic features shaping the landscape of meiotic double-strandbreak hotspots in maize. Proc. Natl. Acad. Sci. U. S. A. 114, 12231-12236. doi: $10.1073 /$ pnas. 1713225114

Henderson, K. A., and Keeney, S. (2004). Tying synaptonemal complex initiation to the formation and programmed repair of DNA double-strand breaks. Proc. Natl. Acad. Sci. U. S. A. 101, 4519-4524. doi: 10.1073/pnas.0400843101

Higgins, J. D., Perry, R. M., Barakate, A., Ramsay, L., Waugh, R., Halpin, C., et al. (2012). Spatiotemporal asymmetry of the meiotic program underlies the predominantly distal distribution of meiotic crossovers in barley. Plant Cell 24, 4096-4109. doi: 10.1105/tpc.112.102483

Higgins, J. D., Sanchez-Moran, E., Armstrong, S. J., Jones, G. H., and Franklin, F. C. (2005). The Arabidopsis synaptonemal complex protein ZYP1 is required for chromosome synapsis and normal fidelity of crossing over. Genes Dev. 19, 2488-2500. doi: 10.1101/gad.354705

Hong, S., Sung, Y., Yu, M., Lee, M., Kleckner, N., and Kim, K. P. (2013). The logic and mechanism of homologous recombination partner choice. Mol. Cell 51, 440-453. doi: 10.1016/j.molcel.2013.08.008 
Ishii, T., Karimi-Ashtiyani, R., and Houben, A. (2016). Haploidization via chromosome elimination: means and mechanisms. Annu. Rev. Plant Biol. 67, 421-438. doi: 10.1146/annurev-arplant-043014-114714

Jacquier, N. M. A., Gilles, L. M., Pyott, D. E., Martinant, J. P., Rogowsky, P. M., and Widiez, T. (2020). Puzzling out plant reproduction by haploid induction for innovations in plant breeding. Nat. Plants 6, 610-619. doi: 10.1038/ s41477-020-0664-9

Jing, J.-L., Zhang, T., Kao, Y.-H., Huang, T.-H., Wang, C. J. R., and He, Y. (2020). ZmMTOPVIB enables DNA double-strand break formation and bipolar spindle assembly during maize meiosis. Plant Physiol. 184, 1811-1822. doi: $10.1104 /$ pp.20.00933

Jing, J.-L., Zhang, T., Wang, Y. Z., and He, Y. (2019). Advances towards how meiotic recombination is initiated: a coparative view and perspectives for plant meiosis research. Int. J. Mol. Sci. 20:4718. doi: 10.3390/ ijms20194718

Jones, G. H., and Franklin, F. C. (2006). Meiotic crossing-over: obligation and interference. Cell 126, 246-248. doi: 10.1016/j.cell.2006.07.010

Khanday, I., Skinner, D., Yang, B., Mercier, R., and Sundaresan, V. (2019). A male-expressed rice embryogenic trigger redirected for asexual propagation through seeds. Nature 565, 91-95. doi: 10.1038/s41586-018-0785-8

Khanday, I., and Sundaresan, V. (2021). Plant zygote development: recent insights and applications to clonal seeds. Curr. Opin. Plant Biol. 59:101993. doi: 10.1016/j.pbi.2020.101993

Kleckner, N. (2006). Chiasma formation: chromatin/axis interplay and the role(s) of the synaptonemal complex. Chromosoma 115, 175-194. doi: 10.1007/ s00412-006-0055-7

Kleckner, N., Zickler, D., Jones, G. H., Dekker, J., Padmore, R., Henle, J., et al. (2004). A mechanical basis for chromosome function. Proc. Natl. Acad. Sci. U. S. A. 101, 12592-12597. doi: 10.10732/Fpnas.0402724101

Labroo, M. R., Studer, A. J., and Rutkoski, J. E. (2021). Heterosis and hybrid crop breeding: a multidisciplinary review. Front. Genet. 24:643761. doi: $10.3389 /$ fgene. 2021.643761

Lam, I., and Keeney, S. (2015). Nonparadoxical evolutionary stability of the recombination initiation landscape in yeast. Science 350, 932-937. doi: 10.1126/ science.aad0814

Lamb, J. C., Yu, W., Han, F., and Birchler, J. A. (2007). Plant chromosomes from end to end: telomeres, heterochromatin and centromeres. Curr. Opin. Plant Biol. 10, 116-122. doi: 10.1016/j.pbi.2007.01.008

Lambing, C., Franklin, F. C., and Wang, C. R. (2017). Understanding and manipulating meiotic recombination in plants. Plant Physiol. 173, 1530-1542. doi: $10.1104 /$ pp.16.01530

Lambing, C., Kuo, P. C., Tock, A. J., Topp, S. D., and Henderson, I. R. (2020a). ASY1 acts as a dosage-dependent antagonist of telomere-led recombination and mediates crossover interference in Arabidopsis. Proc. Natl. Acad. Sci. U. S. A. 117, 13647-13658. doi: 10.1073/pnas.1921055117

Lambing, C., Osman, K., Nuntasoontorn, K., West, A., Higgins, J. D., Copenhaver, G. P., et al. (2015). Arabidopsis PCH2 mediates meiotic chromosome remodeling and maturation of crossovers. PLoS Genet. 11:e1005372. doi: 10.1371/journal.pgen.1005372

Lambing, C., Tock, A. J., Topp, S. D., Choi, K., Kuo, P. C., Zhao, X., et al. (2020b). Interacting genomic landscapes of rec8-cohesin, chromatin, and meiotic recombination in Arabidopsis. Plant Cell 32, 1218-1239. doi: 10.1105/ tpc. 19.00866

Lee, D. H., Kao, Y. H., Ku, J. C., Lin, C. Y., Meeley, R., Jan, Y. S., et al. (2015). The axial element protein desynaptic2 mediates meiotic double-strand break formation and synaptonemal complex assembly in maize. Plant Cell 27, 2516-2529. doi: 10.1105/tpc.15.00434

Leflon, M., Grandont, L., Eber, F., Huteau, V., Coriton, O., Chelysheva, L., et al. (2010). Crossovers get a boost in brassica allotriploid and allotetraploid hybrids. Plant Cell 22, 2253-2264. doi: 10.1105/tpc.110.075986

Li, Q., Eichten, S. R., Hermanson, P. J., Zaunbrecher, V. M., Song, J., Wendt, J., et al. (2014). Genetic perturbation of the maize methylome. Plant Cell 26, 4602-4616. doi: 10.1105/tpc.114.133140

Li, X., Li, L., and Yan, J. (2015). Dissecting meiotic recombination based on tetrad analysis by single-microspore sequencing in maize. Nat. Commun. 6:6648. doi: 10.1038/ncomms7648

Libuda, D. E., Uzawa, S., Meyer, B. J., and Villeneuve, A. M. (2013). Meiotic chromosome structures constrain and respond to designation of crossover sites. Nature 502, 703-706. doi: 10.1038/nature12577
Ma, J., Wing, R. A., Bennetzen, J. L., and Jackson, S. A. (2007). Plant centromere organization: a dynamic structure with conserved functions. Trends Genet. 23, 134-139. doi: 10.1016/j.tig.2007.01.004

Mancera, E., Bourgon, R., Brozzi, A., Huber, W., and Steinmetz, L. M. (2008). High-resolution mapping of meiotic crossovers and non-crossovers in yeast. Nature 454, 479-485. doi: 10.1038/nature07135

Marimuthu, M. P., Jolivet, S., Ravi, M., Pereira, L., Davda, J. N., Cromer, L., et al. (2011). Synthetic clonal reproduction through seeds. Science 331:876. doi: $10.1126 /$ science.1199682

Marques, A., and Pedrosa-Harand, A. (2016). Holocentromere identity: from the typical mitotic linear structure to the great plasticity of meiotic holocentromeres. Chromosoma 125, 669-681. doi: 10.1007/s00412-016-0612-7

Marsolier-Kergoat, M. C., Khan, M. M., Schott, J., Zhu, X., and Llorente, B. (2018). Mechanistic view and genetic control of dna recombination during meiosis. Mol. Cell 70, 9-20. doi: 10.1016/j.molcel.2018.02.032

Martini, E., Diaz, R. L., Hunter, N., and Keeney, S. (2006). Crossover homeostasis in yeast meiosis. Cell 126, 285-295. doi: 10.1016/j.cell.2006.05.044

Mcmahill, M. S., Sham, C. W., and Bishop, D. K. (2007). Synthesis-dependent strand annealing in meiosis. PLoS Biol. 5:e299. doi: 10.1371/journal. pbio.0050299

Medhi, D., Goldman, A. S., and Lichten, M. (2016). Local chromosome context is a major determinant of crossover pathway biochemistry during budding yeast meiosis. eLife 5:e19669. doi: 10.7554/eLife.19669

Melters, D. P., Paliulis, L. V., Korf, I. F., and Chan, S. W. (2012). Holocentric chromosomes: convergent evolution, meiotic adaptations, and genomic analysis. Chromosom. Res. 20, 579-593. doi: 10.1007/s10577-012-9292-1

Mercier, R., Mezard, C., Jenczewski, E., Macaisne, N., and Grelon, M. (2015). The molecular biology of meiosis in plants. Annu. Rev. Plant Biol. 66, 297-327. doi: 10.1146/annurev-arplant-050213-035923

Mieulet, D., Aubert, G., Bres, C., Klein, A., Droc, G., Vieille, E., et al. (2018). Unleashing meiotic crossovers in crops. Nat. Plants 4, 1010-1016. doi: 10.1038/s41477-018-0311-x

Mieulet, D., Jolivet, S., Rivard, M., Cromer, L., Vernet, A., Mayonove, P., et al. (2016). Turning rice meiosis into mitosis. Cell Res. 26, 1242-1254. doi: $10.1038 / \mathrm{cr} .2016 .117$

Nageswaran, D. C., Kim, J., Lambing, C., Kim, J., Park, J., Kim, E.-J., et al. (2021). HIGH CROSSOVER RATE1 encodes PROTEIN PHOSPHATASE $\mathrm{X} 1$ and restricts meiotic crossovers in Arabidopsis. Nat. Plants 7, 452-467. doi: 10.1038/s41477-021-00889-y

Nonomura, K., Nakano, F. T., Eiguchi, M., Miyao, A., Hirochika, H., and Kurata, N. (2004). The novel gene HOMOLOGOUS PAIRING ABERRATION IN RICE MEIOSIS1 of rice encodes a putative coiled-coil protein required for homologous chromosome pairing in MEIOSIS. Plant Cell 16, 1008-1020. doi: 10.1105/tpc.020701

Nonomura, K., Nakano, M., Eiguchi, M., Suzuki, T., and Kurata, N. (2006). PAIR2 is essential for homologous chromosome synapsis in rice meiosis I. J. Cell Sci. 119, 217-225. doi: 10.1242/jcs.02736

Osman, K., Algopishi, U., Higgins, J. D., Henderson, I. R., Edwards, K. J., Franklin, F. C. H., et al. (2021). Distal bias of meiotic crossovers in hexaploid bread wheat reflects spatio-temporal asymmetry of the meiotic program. Front. Plant Sci. 12:631323. doi: 10.33892/Ffpls.2021.631323

Osman, K., Yang, J., Roitinger, E., Lambing, C., Heckmann, S., Howell, E., et al. (2018). Affinity proteomics reveals extensive phosphorylation of the brassica chromosome axis protein ASY1 and a network of associated proteins at prophase I of meiosis. Plant J. 93, 17-33. doi: 10.1111/tpj.13752

Pan, J., Sasaki, M., Kniewel, R., Murakami, H., Blitzblau, H. G., Tischfield, S. E., et al. (2011). A hierarchical combination of factors shapes the genome-wide topography of yeast meiotic recombination initiation. Cell 144, 719-731. doi: 10.1016/j.cell.2011.02.009

Panizza, S., Mendoza, M. A., Berlinger, M., Huang, L., Nicolas, A., Shirahige, K., et al. (2011). Spol1-accessory proteins link double-strand break sites to the chromosome axis in early meiotic recombination. Cell 146, 372-383. doi: 10.1016/j.cell.2011.07.003

Pecina, A., Smith, K. N., Mezard, C., Murakami, H., Ohta, K., and Nicolas, A. (2002). Targeted stimulation of meiotic recombination. Cell 111, 173-184. doi: 10.1016/S0092-8674(02)01002-4

Pecinka, A., Fang, W., Rehmsmeier, M., Levy, A. A., and Mittelsten Scheid, O. (2011). Polyploidization increases meiotic recombination frequency in Arabidopsis. BMC Biol. 9:24. doi: 10.11862/F1741-7007-9-24 
Pele, A., Falque, M., Trotoux, G., Eber, F., Negre, S., Gilet, M., et al. (2017). Amplifying recombination genome-wide and reshaping crossover landscapes in brassicas. PLoS Genet. 13:e1006794. doi: 10.1371/journal.pgen.1006794

Penterman, J., Zilberman, D., Huh, J. H., Ballinger, T., Henikoff, S., and Fischer, R. L. (2007). DNA demethylation in the Arabidopsis genome. Proc. Natl. Acad. Sci. U. S. A. 104, 6752-6757. doi: 10.1073/pnas.0701861104

Phillips, D., Jenkins, G., Macaulay, M., Nibau, C., Wnetrzak, J., Fallding, D., et al. (2015). The effect of temperature on the male and female recombination landscape of barley. New Phytol. 208, 421-429. doi: 10.1111/nph.13548

Prosee, R. F., Wenda, J. M., and Steiner, F. A. (2020). Adaptations for centromere function in meiosis. Essays Biochem. 64, 193-203. doi: 10.1042/EBC20190076

Ravi, M., Marimuthu, M. P., and Siddiqi, I. (2008). Gamete formation without meiosis in Arabidopsis. Nature 451, 1121-1124. doi: 10.1038/nature06557

Raz, A., Dahan-Meir, T., Melamed-Bessudo, C., Leshkowitz, D., and Levy, A. A. (2020). Redistribution of meiotic crossovers along wheat chromosomes by virus-induced gene silencing. Front. Plant Sci. 11:635139. doi: 10.3389/ fpls.2020.635139

Robert, T., Nore, A., Brun, C., Maffre, C., Crimi, B., Bourbon, H. M., et al. (2016). The TopoVIB-like protein family is required for meiotic DNA doublestrand break formation. Science 351, 943-949. doi: 10.1126/science.aad5309

Robine, N., Uematsu, N., Amiot, F., Gidrol, X., Barillot, E., Nicolas, A., et al. (2007). Genome-wide redistribution of meiotic double-strand breaks in Saccharomyces cerevisiae. Mol. Cell. Biol. 27, 1868-1880. doi: 10.1128/ MCB.02063-06

Ronceret, A., and Vielle-Calzada, J. P. (2015). Meiosis, unreduced gametes, and parthenogenesis: implications for engineering clonal seed formation in crops. Plant Reprod. 28, 91-102. doi: 10.1007/s00497-015-0262-6

Rowan, B. A., Heavens, D., Feuerborn, T. R., Tock, A. J., Henderson, I. R., and Weigel, D. (2019). An ultra high-density Arabidopsis thaliana crossover map that refines the influences of structural variation and epigenetic features. Genetics 213, 771-787. doi: 10.1534/genetics.119.302406

Sarno, R., Vicq, Y., Uematsu, N., Luka, M., Lapierre, C., Carroll, D., et al. (2017). Programming sites of meiotic crossovers using Spol1 fusion proteins. Nucleic Acids Res. 45:e164. doi: 10.1093/nar/gkx739

Schmidt, C., Fransz, P., Ronspies, M., Dreissig, S., Fuchs, J., Heckmann, S., et al. (2020). Changing local recombination patterns in Arabidopsis by CRISPR/Cas mediated chromosome engineering. Nat. Commun. 11:4418. doi: $10.10382 / F s 41467-020-18277-z$

Seguela-Arnaud, M., Crismani, W., Larcheveque, C., Mazel, J., Froger, N., Choinard, S., et al. (2015). Multiple mechanisms limit meiotic crossovers: top3alpha and two BLM homologs antagonize crossovers in parallel to FANCM. Proc. Natl. Acad. Sci. U. S. A. 112, 4713-4718. doi: 10.1073/ pnas. 1423107112

Sepsi, A., and Schwarzacher, T. (2020). Chromosome-nuclear envelope tethering a process that orchestrates homologue pairing during plant meiosis? J. Cell Sci. 133:jcs243667. doi: $10.1242 /$ jcs. 243667

Serra, H., Lambing, C., Griffin, C. H., Topp, S. D., Nageswaran, D. C., Underwood, C. J., et al. (2018). Massive crossover elevation via combination of HEI10 and recq4a recq4b during Arabidopsis meiosis. Proc. Natl. Acad. Sci. U. S. A. 115, 2437-2442. doi: 10.1073/pnas.1713071115

Shi, W., Ji, J., Xue, Z., Zhang, F., Miao, Y., Yang, H., et al. (2021). PRD1, a homologous recombination initiation factor, is involved in spindle assembly in rice meiosis. New Phytol. 230, 585-600. doi: 10.1111/nph.17178

Shi, J., Wolf, S. E., Burke, J. M., Presting, G. G., Ross-Ibarra, J., and Dawe, R. K. (2010). Widespread gene conversion in centromere cores. PLoS Biol. 8:e1000327. doi: 10.1371/journal.pbio.1000327

Sidhu, G. K., Fang, C., Olson, M. A., Falque, M., Martin, O. C., and Pawlowski, W. P. (2015). Recombination patterns in maize reveal limits to crossover homeostasis. Proc. Natl. Acad. Sci. U. S. A. 112, 15982-15987. doi: 10.1073/pnas.1514265112

Sommermeyer, V., Beneut, C., Chaplais, E., Serrentino, M. E., and Borde, V. (2013). Spp1, a member of the Set1 complex, promotes meiotic DSB formation in promoters by tethering histone $\mathrm{H} 3 \mathrm{~K} 4$ methylation sites to chromosome axes. Mol. Cell 49, 43-54. doi: 10.1016/j.molcel.2012.11.008

Spillane, C., Curtis, M. D., and Grossniklaus, U. (2004). Apomixis technology development-virgin births in farmers' fields? Nat. Biotechnol. 22, 687-691. doi: $10.1038 /$ nbt976

Sprink, T., and Hartung, F. (2014). The splicing fate of plant SPO11 genes. Front. Plant Sci. 5:214. doi: 10.3389/fpls.2014.00214
Stack, S. M., Shearer, L. A., Lohmiller, L., and Anderson, L. K. (2017). Meiotic crossing over in maize knob heterochromatin. Genetics 205, 1101-1112. doi: 10.1534/genetics.116.196089

Stanzione, M., Baumann, M., Papanikos, F., Dereli, I., Lange, J., Ramlal, A., et al. (2016). Meiotic DNA break formation requires the unsynapsed chromosome axis-binding protein IHO1 (CCDC36) in mice. Nat. Cell Biol. 18, 1208-1220. doi: $10.1038 /$ ncb3417

Steiner, F. A., and Henikoff, S. (2015). Diversity in the organization of centromeric chromatin. Curr. Opin. Genet. Dev. 31, 28-35. doi: 10.1016/j.gde.2015.03.010

Su, H., Liu, Y., Liu, C., Shi, Q., Huang, Y., and Han, F. (2019). Centromere satellite repeats have undergone rapid changes in polyploid wheat subgenomes. Plant Cell 31, 2035-2051. doi: 10.1105/tpc.19.00133

Suay, L., Zhang, D., Eber, F., Jouy, H., Lode, M., Huteau, V., et al. (2014). Crossover rate between homologous chromosomes and interference are regulated by the addition of specific unpaired chromosomes in brassica. New Phytol. 201, 645-656. doi: 10.1111/nph.12534

Sun, Y., Ambrose, J. H., Haughey, B. S., Webster, T. D., Pierrie, S. N., Munoz, D. F., et al. (2012). Deep genome-wide measurement of meiotic gene conversion using tetrad analysis in Arabidopsis thaliana. PLoS Genet. 8:e1002968. doi: 10.1371/journal.pgen.1002968

Taagen, E., Bogdanove, A. J., and Sorrells, M. E. (2020). Counting on crossovers: controlled recombination for plant breeding. Trends Plant Sci. 25, 455-465. doi: $10.1016 /$ j.tplants.2019.12.017

Talbert, P. B., and Henikoff, S. (2020). What makes a centromere? Exp. Cell Res. 389:111895. doi: 10.1016/j.yexcr.2020.111895

Tan, F., Zhou, C., Zhou, Q., Zhou, S., Yang, W., Zhao, Y., et al. (2016). Analysis of chromatin regulators reveals specific features of rice DNA methylation pathways. Plant Physiol. 171, 2041-2054. doi: 10.1104/pp.16.00393

Underwood, C. J., Choi, K., Lambing, C., Zhao, X., Serra, H., Borges, F., et al. (2018). Epigenetic activation of meiotic recombination near Arabidopsis thaliana centromeres via loss of $\mathrm{H} 3 \mathrm{~K} 9 \mathrm{me} 2$ and non-CG DNA methylation. Genome Res. 28, 519-531. doi: 10.1101/gr.227116.117

Voelkel-Meiman, K., Johnston, C., Thappeta, Y., Subramanian, V. V., Hochwagen, A., and Macqueen, A. J. (2015). Separable crossover-promoting and crossoverconstraining aspects of zip1 activity during budding yeast meiosis. PLoS Genet. 11:e1005335. doi: 10.1371/journal.pgen.1005335

Vrielynck, N., Chambon, A., Vezon, D., Pereira, L., Chelysheva, L., De Muyt, A., et al. (2016). A DNA topoisomerase VI-like complex initiates meiotic recombination. Science 351, 939-943. doi: 10.1126/science.aad5196

Wang, Y., and Copenhaver, G. P. (2018). Meiotic recombination: mixing it up in plants. Annu. Rev. Plant Biol. 29, 577-609. doi: 10.1146/annurevarplant-042817-040431

Wang, C., Liu, Q., Shen, Y., Hua, Y., Wang, J., Lin, J., et al. (2019a). Clonal seeds from hybrid rice by simultaneous genome engineering of meiosis and fertilization genes. Nat. Biotechnol. 37, 283-286. doi: 10.1038/ s41587-018-0003-0

Wang, S., Veller, C., Sun, F., Ruiz-Herrera, A., Shang, Y., Liu, H., et al. (2019b). Per-nucleus crossover covariation and implications for evolution. Cell 177, 326-338. doi: 10.1016/j.cell.2019.02.021

Wang, K., Wang, C., Liu, Q., Liu, W., and Fu, Y. (2015). Increasing the genetic recombination frequency by partial loss of function of the synaptonemal complex in rice. Mol. Plant 8, 1295-1298. doi: 10.1016/j.molp.2015.04.011

Wang, K., Wang, M., Tang, D., Shen, Y., Qin, B., Li, M., et al. (2011). PAIR3, an axis-associated protein, is essential for the recruitment of recombination elements onto meiotic chromosomes in rice. Mol. Biol. Cell 22, 12-19. doi: 10.1091/mbc.e10-08-0667

Wang, M., Wang, K., Tang, D., Wei, C., Li, M., Shen, Y., et al. (2010). The central element protein ZEP1 of the synaptonemal complex regulates the number of crossovers during meiosis in rice. Plant Cell 22, 417-430. doi: 10.1105/tpc.109.070789

Wang, S., Zickler, D., Kleckner, N., and Zhang, L. (2015). Meiotic crossover patterns: obligatory crossover, interference and homeostasis in a single process. Cell Cycle 14, 305-314. doi: 10.4161/15384101.2014.991185

Wijnker, E., Deurhof, L., Van De Belt, J., De Snoo, C. B., Blankestijn, H., Becker, F., et al. (2014). Hybrid recreation by reverse breeding in Arabidopsis thaliana. Nat. Protoc. 9, 761-772. doi: 10.1038/nprot.2014.049

Wijnker, E., James, G. V., Ding, J., Becker, F., Klasen, J. R., Rawat, V., et al. (2013). The genomic landscape of meiotic crossovers and gene conversions in Arabidopsis thaliana. eLife 2:e01426. doi: 10.7554/eLife.01426 
Wijnker, E., Van Dun, K., De Snoo, C. B., Lelivelt, C. L., Keurentjes, J. J., Naharudin, N. S., et al. (2012). Reverse breeding in Arabidopsis thaliana generates homozygous parental lines from a heterozygous plant. Nat. Genet. 44, 467-470. doi: 10.1038/ng.2203

Wu, X., and Zhang, Y. (2017). TET-mediated active DNA demethylation: mechanism, function and beyond. Nat. Rev. Genet. 18, 517-534. doi: 10.1038/ nrg.2017.33

Xue, Z., Li, Y., Zhang, L., Shi, W., Zhang, C., Feng, M., et al. (2016). OsMTOPVIB promotes meiotic DNA double-strand break formation in rice. Mol. Plant 9, 1535-1538. doi: 10.1016/j.molp.2016.07.005

Xue, M., Wang, J., Jiang, L., Wang, M., Wolfe, S., Pawlowski, W. P., et al. (2018). The number of meiotic double-strand breaks influences crossover distribution in Arabidopsis. Plant Cell 30, 2628-2638. doi: 10.1105/tpc.18.00531

Yelina, N. E., Gonzalez-Jorge, S., Hirsz, D., Yang, Z., and Henderson, I. R. (2021). CRISPR targeting of MEIOTIC-TOPOISOMERASE VIB-dCas 9 to a recombination hotspot is insufficient to increase crossover frequency in Arabidopsis. bioRxiv [Preprint]. doi: 10.1101/2021.02.01.429210

Yelina, N. E., Lambing, C., Hardcastle, T. J., Zhao, X., Santos, B., and Henderson, I. R. (2015). DNA methylation epigenetically silences crossover hot spots and controls chromosomal domains of meiotic recombination in Arabidopsis. Genes Dev. 29, 2183-2202. doi: 10.1101/gad.270876.115

Yu, H., Wang, M., Tang, D., Wang, K., Chen, F., Gong, Z., et al. (2010). OsSPO11-1 is essential for both homologous chromosome pairing and crossover formation in rice. Chromosoma 119, 625-636. doi: 10.1007/s00412-010-0284-7

Zapata, L., Ding, J., Willing, E. M., Hartwig, B., Bezdan, D., Jiao, W. B., et al. (2016). Chromosome-level assembly of Arabidopsis thaliana Ler reveals the extent of translocation and inversion polymorphisms. Proc. Natl. Acad. Sci. U. S. A. 113, E4052-E4060. doi: 10.1073/pnas.1607532113

Zhang, L., Espagne, E., De Muyt, A., Zickler, D., and Kleckner, N. E. (2014a). Interference-mediated synaptonemal complex formation with embedded crossover designation. Proc. Natl. Acad. Sci. U. S. A. 111, E5059-E5068. doi: $10.1073 /$ pnas. 1416411111

Zhang, L., Kohler, S., Rillo-Bohn, R., and Dernburg, A. F. (2018). A compartmentalized signaling network mediates crossover control in meiosis. elife 7:e30789. doi: 10.7554/eLife.30789.001

Zhang, J., Pawlowski, W. P., and Han, F. (2013). Centromere pairing in early meiotic prophase requires active centromeres and precedes installation of the synaptonemal complex in maize. Plant Cell 25, 3900-3909. doi: 10.1105/ tpc. 113.117846

Zhang, C., Song, Y., Cheng, Z. H., Wang, Y.-X., Zhu, J., Ma, H., et al. (2012). The Arabidopsis thaliana DSB formation (AtDFO) gene is required for meiotic double-strand break formation. Plant J. 72, 271-281. doi: 10.1111/j.1365-313X. 2012.05075.x

Zhang, L., Wang, S., Yin, S., Hong, S., Kim, K. P., and Kleckner, N. (2014b). Topoisomerase II mediates meiotic crossover interference. Nature 511, 551-556. doi: 10.1038/nature13442

Zhang, H., and Zhu, J. K. (2012). Active DNA demethylation in plants and animals. Cold Spring Harb. Symp. Quant. Biol. 77, 161-173. doi: 10.1101/ sqb.2012.77.014936

Zhu, J., Kapoor, A., Sridhar, V. V., Agius, F., and Zhu, J. K. (2007). The DNA glycosylase/lyase ROS1 functions in pruning DNA methylation patterns in Arabidopsis. Curr. Biol. 17, 54-59. doi: 10.1016/j.cub.2006.10.059

Zickler, D., and Kleckner, N. (1999). Meiotic chromosomes: integrating structure and function. Annu. Rev. Genet. 33, 603-754. doi: 10.1146/annurev. genet.33.1.603

Ziolkowski, P. A., Underwood, C. J., Lambing, C., Martinez-Garcia, M., Lawrence, E. J., Ziolkowska, L., et al. (2017). Natural variation and dosage of the HEI10 meiotic E3 ligase control Arabidopsis crossover recombination. Genes Dev. 31, 306-317. doi: 10.1101/gad.295501.116

Conflict of Interest: The authors declare that the research was conducted in the absence of any commercial or financial relationships that could be construed as a potential conflict of interest.

The reviewer SH declared a past co-authorship with one of the authors CL to the handling editor.

Copyright (C) $2021 \mathrm{Kuo}, \mathrm{Da}$ Ines and Lambing. This is an open-access article distributed under the terms of the Creative Commons Attribution License (CC BY). The use, distribution or reproduction in other forums is permitted, provided the original author(s) and the copyright owner(s) are credited and that the original publication in this journal is cited, in accordance with accepted academic practice. No use, distribution or reproduction is permitted which does not comply with these terms. 